\title{
Does Phenomenology Ground Mental Content?
}

\author{
ADAM PAUTZ \\ Fortunately for the determinate character of intentional \\ content, content determinacy is fixed phenomenally. \\ -Graham, Horgan, and Tienson (2007)
}

Many go in for the reductive externalist program concerning the mind and its intentionality. For instance, many have said that at least some beliefs have their contents because their neural realizers bear an appropriate physical relation to certain external conditions. We might call the relevant relation the tracking relation, leaving open whether it is to be explained in terms of causal covariation under optimal conditions (Stalnaker, Tye), asymmetric dependence (Fodor), indicator function (Dretske), or normal conditions for the proper function of output systems (Millikan). ${ }^{1}$

Many extend the same model to the phenomenal side of the mind. They accept intentionalism about experience: the phenomenology of an experience is determined by its intentional content. And they think the content of experience, like the content of belief, is fixed by tracking relations to the environment. The result is phenomenal externalism: the phenomenology of experience is not fixed by what happens in the brain, but by what environmental states the brain tracks. ${ }^{2}$

The reductive externalist program faces many long-standing problems of detail. Among them are the disjunction problem, the distance (depth) problem, and problems about content determinacy due to Quine and Kripkenstein. ${ }^{3}$ Indeed Lycan (2009: note 1) has recently spoken of the "dismal failure" of all existing proposals within the reductive externalist program, suggesting that this provides the best argument for a non-reductive approach to the mind. I agree. The reductive externalist program is in a state of stagnation.

Recently an alternative approach has come to the fore, the phenomenal intentionality program. This program gives a sense of revolution, of upsetting the 
applecart. A number of ideas are loosely associated with it. First, prioritism: phenomenology is "explanatorily prior to" intentionality. Indeed, Horgan and Tienson (2002: 520) define "phenomenal intentionality" as intentionality that is possessed "in virtue of" phenomenology, where this stands for a relation of explanatory priority. So, for instance, sensory experience is richly intentional, and its intentionality is grounded in its phenomenology. Second, phenomenal internalism: roughly, phenomenology, and hence phenomenal intentionality, is internally determined. This is supposed to be intuitively obvious. In consequence, the reductive externalist program is a non-starter. For instance, an accidental, life-long "brain in a vat" might have a rich phenomenal life and stand in various intentional relations to various (false) intentional contents, even though its states do not have the function of tracking the environment. Third, phenomenal liberalism: in addition to sensory phenomenology, there is such a thing as cognitive phenomenology. And, just as sensory phenomenology grounds the content of sensory experience, cognitive phenomenology helps ground the content of cognitive states. This is supposed to finally solve the long-standing problems raised by Quine, Kripkenstein, and others concerning content determinacy.

If one wanted a single slogan for the phenomenal intentionality program, it might be phenomenology first or maybe consciousness first. ${ }^{4}$ The core thesis is that phenomenology plays a foundational role in grounding all intentionality. As for the nature of phenomenology itself, proponents of the program have had very little to say. For instance, they have not said whether it is possible to provide a reductive internalist theory of phenomenology and intentionality, which can be put in the place of standard reductive externalist ("tracking") theories. They tend to ignore the whole hard problem of naturalizing the mind. While the externalist program is reductive, the phenomenal intentionality program might go best with a non-reductive approach.

In general, my own views fall within the vague boundaries of the phenomenal intentional program. While I think that the specific theses associated with the phenomenal intentionality program are very underdeveloped and poorly motivated, I also think that there are defensible theses in the vicinity. ${ }^{5}$ In this chapter, I will be focused on one thesis in particular, the thesis that "cognitive phenomenology" might help ground mental content. First (\$1-2) I will argue that this thesis is very underdeveloped and poorly motivated. Then (§3) I will develop several arguments against it. (Here I will address the largely ignored issue of whether phenomenal intentionality might be naturalized.) Finally $(\S 4)$, I will defend a claim in the same vicinity. On my view, it is sensory phenomenology, not "cognitive phenomenology," that is the source of all determinate intentionality. To explain how, I will draw on some of David Lewis's ideas concerning intentionality. 


\section{Preliminaries: Cognitive Phenomenology}

To begin with, I clarify the thesis that I will criticize, namely, the thesis that cognitive phenomenology plays an important role in grounding mental content.

Consider an example due to Horgan and Tienson (2002). You hear "Visiting relatives can be boring" first as a remark about the people who are visiting and then as a remark about visiting certain people oneself. Horgan and Tienson say that the actual sound or auditory imagery may be the same, but the total experiences are phenomenally different. They conclude that the two occurrent beliefs differ in non-sensory phenomenology. Let cognitive phenomenology be the phenomenology (if such there be) that attaches to beliefs and other intentional states that is distinct from associated sensory phenomenology, where sensory phenomenology is understood broadly to include perceptual, bodily, imagistic, and emotional phenomenology. Horgan and Tienson say (2002: 522) that cognitive phenomenology is quite rich: "Change either the attitude-type (believing, desiring, wondering, hoping, etc.) or the particular intentional content, and the phenomenal character thereby changes too." So, for instance, they believe in a special non-sensory, conative phenomenology that helps individuate our desires. (I will use "cognitive phenomenology" broadly, so that it also covers conative phenomenology.) Call the minimal thesis that there is such a thing as cognitive phenomenology the CP-existence thesis. This thesis has been widely discussed (see Montague 2010 for a helpful overview).

Many put forward a second, much stronger thesis about cognitive phenomenology that has not been widely discussed. It will be my primary focus. Here are some representative passages:

How can [cognitive] experience ever deliver determinateness? It just can. Cognitive experience in causal context can do just this. Such is its power. (When it comes to [thinking of] the number 2, it doesn't even require causal context.)... If God could look into my mind and apprehend the cognitive [phenomenology] of my experience he would certainly know what I was thinking about, given that he also knewand how could he not-about my causal circumstances. It is the same power that makes it the case that I can think determinately about the number 2 although there is no relevant causal context. Pfff! This is the correct account of how it is that content can be determinate in spite of all the problems raised for this idea by Kripke in his book Wittgenstein on Rules and Private Language. (Strawson 2010: 351, 354)

The part of what is thought that is fully determined by [cognitive] phenomenal character [is] a kind of thought content. (Siewert 2011) 
[E]ach specific occurrent intentional state with phenomenal intentional content is constitutively determined by its own distinct phenomenal character-viz., the what-it's-like of undergoing that particular attitude-type vis-à-vis that particular phenomenal intentional content... Suppose that you are now undergoing a psychological state with the distinctive [non-sensory] phenomenal what-it's-like of believing that a picture is hanging crooked on a wall directly behind you. Then you thereby believe that there is a picture hanging crooked on a wall directly behind you; undergoing this phenomenology constitutively determines that you are instantiating that belief-state. Any experiencing creature [e. g. a brain in a vat] undergoing this phenomenology would thereby instantiate the belief-state, even if its overall phenomenology is otherwise quite different from your own. (Horgan and Tienson 2002: 526)

Physically and apart from phenomenology, there is no "one, determinate, right answer" to the question of what is the content of an intentional state. For ... the content of each mental state is not determinately fixed once the physical facts (including perhaps physical facts about the internal-environmental linkages) are fixed. Fortunately, however, for the identity or determinate character of intentional content, content identity or determinacy is fixed phenomenally. For example, the what-it's-like of thinking "Lo, a rabbit" is different from the what-it's-like of thinking "Lo, a collection of undetached rabbit parts"... [This] commitment to phenomenal individuation of intentional content, combined with rejection of physical individuation, [might be] tantamount to dualism. (Graham, Horgan and Tienson 2007: 476, 481)

You know what you are thinking and what you mean by your utterance, and there is a determinate fact of the matter about what you are thinking and what you mean by your utterance, because there is something it is like to think a determinate thought and to make an utterance that expresses that thought. Developing in detail our proposed account of content determinacy is... an agenda item for the future. (Horgan and Graham 2010)

[My view] maintains that the intentional content of a thought is determined by its intrinsic phenomenal properties, not its relational properties. My teachers will be very disappointed in me. (Pitt 2009: note 5, my italics) 
Let a cognitive phenomenal property be a property of individuals of the form having a state with such-and-such cognitive phenomenology. All of the quoted philosophers apparently endorse the following CP-determination thesis: for at least some cognitive phenomenal properties $P$, there is a unique content $c$ such that it is metaphysically necessary that, if an individual simply has $P$, then he has an occurrent belief (or desire) with content $c{ }^{6}$

Now this idea is not new. Kripke (1982: 42) took it seriously. But he compared cognitive experiences to mere "raw feels" or bits of "mental paint," like undirected depression. Against this, CP-determination says that they have built-in intentionality, just as perceptual experiences arguably have built-in intentionality.

Let me make some clarifications. First, CP-determination is only meant to apply to our occurrent beliefs (also sometimes called thoughts or judgments) and our occurrent desires. It cannot be applied to our unconscious, standing beliefs and desires, which certainly lack phenomenology. To explain such beliefs and desires, the proponent of CP-determination needs a different account (for some options see Graham, Horgan, and Tienson 2007). This will not concern us here. Second, on the assumption that it is "intrinsic," cognitive phenomenology of course cannot determine the "wide contents" of our beliefs and desires which can differ between internal duplicates: natural kind contents (for example, about water or rabbits), singular contents (for example, contents involving a particular river), and so on. Consequently, proponents of $\mathrm{CP}$-determination typically only claim that cognitive phenomenology determines the narrow (and perhaps "centered," de se) contents of beliefs and desires that do not differ between such duplicates. In this category they include mathematical contents (Strawson mentions contents about the number 2), certain general descriptive de se contents (the watery stuff of my acquaintance is wet), artifactual contents (Horgan and Tienson mention a content about a picture), and so on. To explain wide content, Horgan and Tienson (2002) adopt David Lewis's (1994) view that wide content is derivative from narrow content and relations to the environment.

The approach taken by proponents of the CP-determination thesis is interesting, for two reasons. First, it is unorthodox. The puzzle of intentionality can be put like this: how is it that one manages to stand in intentional relations to some contents rather than others? (Here and I assume that to have a particular belief or desire is to stand in the belief relation or the desire relation to a particular proposition or "content.") According to orthodoxy:

- The contents of the (occurrent and non-occurrent) beliefs and desires of a subject are always determined by features of the subject that go beyond his intrinsic properties at the time he has those beliefs and desires: factors such as environment-involving behavioral dispositions, tracking relations to the 
environment, causal or inferential relations among internal states, what sentences he accepts and their contents as determined by their overall pattern of use in the language, and so on.

Granted, many philosophers, for instance David Lewis and Frank Jackson, do recognize a notion of non-Twin-Earthable "narrow content." But Lewis and Jackson repeatedly emphasize that, on their weak notion of "narrow content," having a mental state with a particular narrow content is not entirely intrinsic, because narrow contents are determined by the typical world-involving functional roles of your internal states in your population, which are not intrinsic.?

By contrast, proponents of CP-determination typically accept the radical phenomenal internalism associated with the phenomenal intentionality program: all phenomenal properties (and hence cognitive phenomenal properties) are intrinsic, and hence non-functional, properties of individuals (see the quote from Pitt, and also Horgan, Tienson, and Graham 2004). (This is not obligatory: as we shall see in $§ 3.1$, one could accept the CP-determination thesis but reject the intrinsicness thesis.) When this is combined with $\mathrm{CP}$-determination, we get:

- Some of a subject's occurrent beliefs and desires have contents that are fully determined by certain of his intrinsic properties at the time he has those occurrent beliefs and desires (namely, cognitive phenomenal properties), where the relevant intrinsic properties are distinct from all of his sensory and functional properties (past, present and future).

There is a second reason that the CP-determination thesis is interesting: many declare that it finally solves content determinacy worries due to Quine and Kripkenstein.

Here is a rough formulation of the Kripkenstein problem as it arises for physicalists. Let quus , quus $_{2}$, quus ${ }_{3}$ denote different functions defined over numbers that are just like the plus function but that differ from the plus function only when it comes to numbers that are too large for us to compute. Then, at least if we set aside the widely rejected view that necessarily equivalent propositions are identical, there are infinitely many distinct contents up in Plato's heaven: that two plus two equals four, that two quus ${ }_{1}$ two equals four, that two quus ${ }_{2}$ two equals four, that two quus ${ }_{3}$ two equals four, and so on. If we say that the non-intentionally characterized functional and behavioral facts determine (in the sense of metaphysically necessitate) that one believes one of these contents (in particular, that two plus two equals four) to the exclusion of all the others, then we want some kind of explanation for this. How do these facts select or point to that particular content to be what you believe? Is there a physicalist-functionalist (perhaps a posteriori) account of the belief relation 
that explains how the physical facts determine that this is the content you believe, as opposed to the other candidates? In my view, the main problem here is the problem of finitude. We have (non-intentionally characterizable) dispositions involving a certain finite set of numerals in language (and perhaps in the language of thought) but we do not have dispositions involving numerals that are too long for us to compute. Quine's well-known problem about rabbits and undetached rabbit-parts is similar to the Kripkenstein problem.

In the passages cited earlier, Strawson as well as Graham, Horgan, and Tienson declare that in such cases cognitive phenomenology saves the day: somehow it manages to determine what content you believe.

The CP-determination thesis is underdeveloped. One does not get much more than the bare assertion that cognitive phenomenology determines content. This leaves many obvious questions unanswered. What exactly is the relationship between cognitive phenomenal properties and intentional properties? What is the relationship between cognitive phenomenal properties and physical-functional properties? Is phenomenal intentionality a natural phenomenon? I will be looking at these questions.

I will argue that, even if the CP-existence thesis is true, the stronger and more interesting $\mathrm{CP}$-determination thesis is not. Along the way I will present some novel reasons to doubt the $\mathrm{CP}$-existence thesis as well.

\section{The CP-Determination Thesis as Unmotivated}

Let us first look at arguments for the CP-determination thesis. Contrary to some proponents, it is not introspectively obvious, since many reject it. I will consider two arguments for $\mathrm{CP}$-determination, suggesting that they fall short.

\subsection{First Argument: The Determinacy Argument}

In several places, Graham, Horgan, and Tienson have briefly argued for $\mathrm{CP}$-determination on the grounds that it provides the only adequate solution to the determinacy problems due Quine and Kripkenstein, as follows:

1 Against Quine and Kripkenstein, there generally are determinate facts about what we believe and mean.

2 But Quine and Kripkenstein are right that such facts could not be "determinately fixed by" the physical facts.

3 If premise 2 is true, then there could be determinate facts about what we believe and mean only if they are fixed by non-sensory, cognitive phenomenology: this is the only alternative to physical determination. 
4 So, there could be determinate facts about what we believe and mean only if they are fixed by cognitive phenomenology. $(2,3)$

5 So, what we believe and mean is fixed by cognitive phenomenology. $(1,4)^{8}$

There are several problems with this argument.

(i) Against premise 2, there are numerous important physicalist answers to Quine and Kripkenstein's arguments in the literature on "naturalizing intentionality." But Graham, Horgan, and Tienson do not provide an in-principle reason to think that all they fail, nor do they eliminate them one by one.

(ii) In support of premise 3, Graham, Horgan, and Tienson (2009: 531) say that if we "[agree] with Quinean misgivings about the physical determination of content, then all that's left as a mode of individuation is phenomenological individuation." From the examples they discuss (they speak of the what-it's-like of thinking "Lo, a rabbit") it is clear they mean cognitive phenomenology and not mere sensory phenomenology; and Horgan and Graham (2010) explicitly say that cognitive phenomenology over and above sensory phenomenology is needed to secure our actual level of content determinacy. Otherwise they do not have an argument from determinacy for cognitive phenomenology.

But they largely ignore certain views on which sensory phenomenology is an important source of content determinacy. On some views, sensory phenomenology is richly intentional (for example, essentially involves the representation of observational properties), but its intentionality is not reducible to purely physical facts (Pautz 2010a; Chalmers 2006). Further, our actual and potential sensory experiences, together with the functional facts, are enough to secure our actual level of content determinacy. The proponent of this view shares Quine's misgivings about the physical determination of content in a sense: he agrees that facts about determinate content are not fixed merely by the third-person physical facts - for instance, non-intentionally characterizable behavioral and functional facts. But he denies that the only alternative to austere physicalism involves the appeal to non-sensory, cognitive phenomenology. Later (in §4) I will recommend this view as an alternative to $\mathrm{CP}$-determination.

How could Graham, Horgan, and Tienson show that this view is wrong, and that they are right in maintaining that cognitive phenomenology over and above sensory phenomenology is needed to secure the level of content determinacy that our intentional states actually possess? They would need to show that a community which is exactly like us in all physical respects and all actual and dispositional sensory respects (same sensory experiences with their built-in intentionality, same language, etc.), but which lacks the occasional extra bits of "cognitive phenomenology" that we allegedly enjoy (an absent cognitive qualia case), would differ profoundly from us in having intentional states whose contents are much less 
determinate than the contents of our actual intentional states. They would have to show that sensory-functional supervenience fails: total intentional facts about a population fail to supervene on the total sensory and functional facts about that population. (Uriah Kriegel asked me whether such an absent cognitive qualia case is nomically possible. But for the point I am making the case only needs to be metaphysically possible, and in §3.2 I will argue that it is.) But Graham, Horgan, and Tienson have certainly not shown this or even addressed the supervenience issue. How could they show this? Later on I will argue that the sensory-functional supervenience thesis is actually correct (§§3.2-3.3).

(iii) In maintaining that the only alternative to physical determination is determination by cognitive phenomenology (premise 3), Horgan and Tienson ignore yet another option, one that is historically well known. As Boghossian (1989: 542) notes, Brentano's thesis of the irreducibility of intentional idioms answers Kripkenstein and secures content determinacy but does not require cognitive phenomenology. So considerations concerning content determinacy alone simply do not justify acceptance of CP-determination at all. Horgan and Tienson cannot object to primitivism. As we will see (§3.1), their own brief remarks suggest a primitivist (or, as they themselves say in the passage cited earlier, "dualist") view of content determinacy.

(iv) Finally, against premise 1, one might say that, while perhaps some of our beliefs clearly determinately possess certain contents (for example, immediate perceptual beliefs) thanks to having an especially close connection to sensory experience, other beliefs (beliefs about electrons, arithmetical beliefs) must be admitted to be radically indeterminate in content.

In response, Horgan and Graham (2010) would claim that in general content determinacy “is just obvious," even though Quine and many others have rejected it. But how can introspection deliver certainty concerning this disputed, highly theoretical issue? Further, according to Horgan and Graham, in the absent cognitive qualia case mentioned earlier, when their own counterparts (sensory-functional duplicates) say (just as Horgan and Graham do) that "in general there is content determinacy," their counterparts are giving expression to a false introspective belief, for their counterparts in this case lack the cognitive qualia which, according to them, are necessary for securing general content determinacy. So by their own lights introspection is highly fallible when it comes to the highly theoretical issue of content determinacy.

\subsection{Second Argument: The Access Argument}

Very roughly, the first premise of this argument-defended for instance by Pitt (2011) — is that one has some kind of "special access" to one's occurrently believing or desiring that $p$. The second premise is that this requires that occurrently 
believing or desiring that $p$ have an "individuative" cognitive phenomenology, in a sense that entails CP-determination.

But there are two problems with the second premise of this interesting argument. First, many accounts of special access do not require $\mathrm{CP}$-determination. Indeed, even Pitt's own theory - which a kind of direct acquaintance theory - does not require that our occurrent thoughts be phenomenal states. There is nothing in the notion of acquaintance that demands that we are only acquainted with phenomenal states. Russell (1912: 105) explicitly allowed for acquaintance with non-phenomenal states, for instance two plus two equaling four. So what exactly is the argument against a view on which our occurrent thoughts are non-phenomenal states but we have immediate, acquaintance-based knowledge of them? ${ }^{9}$ Many other accounts of special access do not require CP-determination (for example, Byrne 2011, Carruthers 2011). Pitt criticizes some of these models. But (although I cannot discuss this here) I think his criticisms are not decisive. Further, he does not eliminate all possible models.

A second problem is this. Consider once again the absent cognitive qualia case. It is exactly like the actual case in all respects (sensory, perceptual, functional, physical) except that our counterparts lack cognitive qualia. The second premise of the access argument has a very radical consequence: that in this case our counterparts could not enjoy the same kind of special, non-inferential access to occurrent beliefs and desires that we enjoy. But there are reasons to reject this consequence. To begin with, they clearly have occurrent beliefs and desires with some contents, despite lacking cognitive phenomenology. (Whether their contents are just as "determinate" as the contents of our beliefs and desires does not matter to the point I am trying to make here, namely, that special access to content doesn't in general require CP-determination.) They are not cognitive zombies. So, for instance, suppose my counterpart, like me, currently has an experience of a round tomato; the sentence "that's a round tomato" runs through his inner speech and he also assents to this sentence in public speech; and he manifests understanding this sentence just as I do. Suppose he also has strong hunger pangs, imagines food, and has experiences of seeking food; the sentence "food would be good" runs through his inner speech and he assents to this sentence in public speech; and he manifests understanding this sentence just as I do. No one competent with the concepts of belief and desire would deny that, like me, he believes a round tomato is present and that he desires food; and there is no theory-neutral reason to deny these things. Moreover, like me, without having to go through any conscious process of inference, my counterpart assents to the sentences "I believe that's a round tomato" and "I desire food" and exhibits full understanding of these sentences and mastery of the concepts of belief and desire. So no one would deny that he also has introspective beliefs about his belief and desire. Now these introspective beliefs have all the earmarks of knowledge; they are, for instance, non-accidentally true. What 
reason is there to deny that they constitute knowledge? Perhaps it will be said that from my counterpart's point of view these introspective beliefs pop up "out of the blue" (as in familiar cases of unwitting reliability discussed by epistemologists). As against this, they are quite in line with his experiential life, for instance, his inner speech and experienced behavior. The conclusion I draw is that my counterpart also has immediate access to his beliefs and desires, despite his lack of "cognitive phenomenology." Special access doesn't require cognitive phenomenology.

\section{Against CP-Determination}

No convincing argument for the CP-determination thesis has yet been provided. I will now develop several arguments against it.

\subsection{First Argument: The Danglers Argument}

My first argument is that there are reasons to interpret proponents of CP-determination as "anti-reductionists" or "primitivists" about cognitive phenomenology and hence cognitive intentionality. They accept what is sometimes called Brentano's thesis (Quine 1960: 221). But, if they reject reductionism and accept primitivism, they need brute principles or "danglers" (Smart 1959) connecting cognitive phenomenology with mainstream physical properties.

Let me first argue in some detail for the "primitivist" interpretation. According to proponents of CP-determination, what is the nature of cognitive phenomenology, such that it delivers determinate content? They never say. They might take a reductive physicalist view of cognitive phenomenology and phenomenal intentionality in general. Here I understand reductive views broadly to include views that identify mental properties with physical properties and physically realized functional properties. There are two types of reductive physicalist theories of sensory phenomenology: biological theories and functional theories. Proponents of CP-determination might apply the same reductive theories to cognitive phenomenology, thereby avoiding the need to postulate brute principles or "danglers" to explain its presence in the world. But there is reason to think that they would not.

To see this, consider first a biological theory of cognitive phenomenology, akin to the familiar biological (type-type identity) theory of sensory phenomenology. To illustrate, let $P$ be the non-sensory phenomenal property you allegedly possess when you occurrently believe that two plus two equals four on a certain occasion. On the biological theory of cognitive phenomenology, $P$ is necessarily identical with the intrinsic neuro-computational property $M$, which has its connections with the external world and behavioral outputs only contingently. 
This might be the only naturalistic theory compatible with the radical phenomenal internalism favored by friends of the phenomenal intentionality program, according to which phenomenal properties are intrinsic properties of individuals.

Let biological CP-determination be the conjunction of CP-determination and the biological theory of cognitive phenomenology. This conjunction entails that, for some narrow (non-Twin-Earthable) beliefs and desires with content $c$, there is a single neural state that metaphysically necessitates having a belief or desire content $c$. For instance, on CP-determination, having cognitive phenomenal property $P$ determines as a matter of metaphysical necessity believing two plus two equals four. On the biological theory of cognitive phenomenology, $P$ is necessarily identical with neuro-computational property $M$. Hence, according to biological CP-determination, merely having the mere neuro-computational property $M$ determines as a matter of metaphysical necessity believing two plus two equals four. Another neural property metaphysically necessitates believing there is a picture on the wall behind oneself. And so on. Of course, the biological theory might also be applied to sensory intentionality. Maybe, for instance, there is a neural property that necessitates being visually acquainted with the general property roundness (Horgan, Tienson, and Graham 2004).

Might proponents of $\mathrm{CP}$-determination accept biological CP-determination? Is the biological theory a plausible model for "naturalizing" phenomenal intentionality? I think not.

First, belief and other standard intentional states must be taken to be relations to intentional contents or properties or other abstract objects. Those attracted to non-relational accounts of intentionality (for example, Kriegel 2011: chap. 3) have not answered the very strong arguments for the standard relational view (for example, Schiffer 2006). So, for instance, the proponent of biological CP-determination must recognize the existence of a two-place belief relation $B_{\mathrm{n}}$ that we bear to "narrow contents."

Now the proponent of biological CP-determination already reduces monadic cognitive phenomenal properties to monadic neuro-computational properties. So he doesn't need brute laws or "danglers" to explain the correlations between these properties. Could he also provide a reductive account of the dyadic relation $B_{\mathrm{n}}$ ? Could he identify it with some dyadic physical or functional relation between individuals and narrow contents (abstract objects), such that what contents you bear this relation to (two plus two is four, there is a picture on the wall, etc.) are somehow fixed merely by your intrinsic neural properties?

The same problem arises concerning other intentional relations. Horgan, Tienson, and Graham (2004: 304-305) claim that there are many existing things (for instance, abstract objects like numbers and general properties like being a picture or being round) such that your thinking about them is fixed simply 
by your narrow, intrinsic neutral properties. Might they provide a reductive account of this narrow thinking-about relation, $T_{n}$ ?

This is a huge problem, but elsewhere I have argued that the answer is "No."10 To appreciate the argument, consider that biological CP-determination has the consequence that an accidental, isolated brain-in-a-vat might bear the relation $T_{n}$ to the number four, the property of being a picture, the property of being round, and so on. But by stipulation it does not bear the usual tracking, behavioral, or other physical relations to these entities, which are appealed to in all existing naturalistic theories. How then could $T_{n}$ be a physical relation? If we confine ourselves to intrinsic neural features (firing rates, causal relations among uninterpreted mentalese sentences) and do not appeal to relations to the environment and behavior to pin down content, then a reduction is out of the question. There is no general algorithm, applying to all actual or possible individuals, that goes merely from these intrinsic features to what items (properties like shapes, mathematical objects) an individual is thinking of $_{\mathrm{N}}$ and what narrow contents he believes ${ }_{\mathrm{N}}$. So the defender of biological $\mathrm{CP}$-determination must take $T_{\mathrm{n}}$ and $B_{\mathrm{n}}$ to be primitive relations, thus frustrating his reductive ambitions. A corollary of this is that he would have to accept "brute necessities." He wouldn't after all avoid the kind of "modal danglers" that type-type identity is designed to avoid (Smart 1959). For instance, he would have to say that it is brute necessity that neural duplicates must bear the primitive intentional relations $B_{n}$ and $T_{n}$ to the same contents (two plus two is four, there is a picture on the wall) and other abstract objects (numbers, general properties). ${ }^{11}$ And it is just a brute (and fortunate) fact that they bear these relations to plus-contents rather than "bent," quus-like contents, so that there is no interesting solution to Kripkenstein puzzle. It is not merely that he would have to say that these necessities are brute in the epistemic sense that they are not a priori knowable (most physicalists accept such epistemic bruteness). He would have to say that they are brute in a more objectionable metaphysical sense (roughly along the lines of Dorr 2007): they cannot be derived from any more basic modal truths.

There is another problem. Biological CP-determination is open to what we might call the "separation argument." (Pautz (2010c: sect. 4) develops the same line of argument against biological theories of sensory intentionality.) According to biological CP-determination, having the mere neuro-computational property $M$ metaphysically necessitates believing that two plus two equals four. Against this, there are possible "separation cases" in which $M$ (perhaps just a bit of brain-writing in the "cognitive phenomenology" center of the brain) is totally functionally isolated and plays no interesting functional role with respect to experiencing collections of objects and the experience of counting objects, imagery, and so on (cf. the "baby case" in §3.2). There are also worlds in which it plays such a functional role, but one appropriate to a quite different arithmetical belief (for example, five plus five equals ten). In these cases 
$M$ is "separated from" its actual sensory-functional role. It would be absurd to suggest that in these possible cases $M$ realizes believing that two plus two equals four. So, contrary to biological $\mathrm{CP}$-determination, possessing the mere neuro-computational property $M$ does not metaphysically necessitate believing that two plus two equals four.

So those who favor CP-determination should not accept biological $\mathrm{CP}$-determination for the simple reason that it is bad theory. Against biological CP-determination, most think that it is the connections our internal neural states bear to the world and behavior that link them to some contents and not others. Accordingly, the friend of CP-determination might instead consider providing a reductive functionalist theory of the cognitive phenomenal properties which in their view determine intentional content.

To illustrate, consider a non-arithmetical example. In the passage quoted in $\S 1$, Horgan and Tienson say that there is a unique cognitive phenomenal property that metaphysically necessitates believing that there is a picture hanging on the wall behind one. Call it $P$ for "picture." By contrast to the proponent of a biological theory of phenomenal properties, the reductive functionalist I have in mind will identify $P$ with some kind of functional property defined in terms of external inputs and behavioral outputs. Here I understand functional properties broadly to include historically determined "tracking" relations to the environment. Let functional CP-determination be the conjunction of the $\mathrm{CP}$-determination thesis and some functionalist theory of cognitive phenomenal properties.

Thus, suppose that $L$ is the functional property that David Lewis (1994) would say constitutes occurrently believing that there is a picture hanging on the wall behind one. The proponent of functional CP-determination might say that the cognitive phenomenal property $P$ just is the Lewisian functional property $L$. Or again, suppose that $F$ is the functional property that Jerry Fodor (1994) would say constitutes having the same occurrent belief. It might involve the tokening of a mentalese sentence, functional role, and relations of "asymmetric-dependence" to the external world. According to another version of functional CP-determination, the cognitive phenomenal property $P$ just is the environment-involving functional property $F$. So, cognitive phenomenology and hence cognitive intentionality is not in the head, just as some intentionalists about experience insist that sensory phenomenology is not in the head (as noted in the introduction). According to any version of functional $\mathrm{CP}$-determination, cognitive phenomenal properties constitute intentional properties, because they are identical with functional properties and those functional properties constitute intentional properties.

Now friends of $\mathrm{CP}$-determination could accept functional CP-determination, thereby providing a "naturalistic" theory of how cognitive phenomenal properties ground intentionality. True, rejecting biological CP-determination and 
accepting functional $\mathrm{CP}$-determination would require rejecting the thesis that cognitive phenomenal properties are intrinsic; but I never built that into the formulation of CP-determination. As I have pointed out elsewhere (Pautz 2008: 272-273), what is arguably the core thesis of the phenomenal intentionality program-namely, that phenomenology is in some sense the source of all intentionality-is quite compatible with reductive externalist (for example, tracking) theories of phenomenology. Recently, Kriegel (2011: 69, 249) has made the same point and has developed it into a whole theory. He says he is strongly attracted to a version of functional CP-determination. In particular, he favors a higher-order tracking theory of phenomenal intentionality (109). However, while Kriegel favors functional CP-determination, I think other friends of phenomenal intentionality will reject it, given their other commitments.

(i) As noted in $§ 1$, Horgan and coauthors as well as Pitt hold that cognitive phenomenal properties are intrinsic and "non-relational." This rules out functional CP-determination, since the relevant functional properties are non-intrinsic. ${ }^{12}$

(ii) As noted (\$2.1), Horgan and coauthors reject all orthodox physicalist solutions to the determinacy problems due to Quine and Kripkenstein. They appear to hold that the functional facts are insufficient to constitute (or even "fix") the intentional facts. But, according to functional $\mathrm{CP}$-determination, the functional facts do constitute the intentional facts. For, according to functional $\mathrm{CP}$-determination, the cognitive-phenomenal facts constitute the intentional facts; further, they are identical with certain functional facts; so (by Leibniz's law) the functional facts constitute the intentional facts.

(iii) Presumably, fans of the phenomenal intentionality program would say that their claim that phenomenology grounds intentionality plays an essential role in avoiding the well-known problems of detail plaguing the reductive externalist program and the naturalization program more generally. But those who favor functional CP-determination (Kriegel 2011: 109) cannot say this. As just noted, like standard naturalists, they are committed to saying that certain naturalistic facts (about functional role, inferential role, tracking, and so on) constitute the intentional facts. So they face the standard problems of detail with that claim. For instance, they are committed to the existence of a general, non-circular, counterexample-free naturalistic account of intentionality of the form state $S$ has content $C$ iff $S$ satisfies naturalistic condition $F$, despite the "dismal history" of failed attempts to provide such an account. They face the disjunction problem, the depth (distance) problem, Kripke's problem of finitude, and Quine's inscrutability problem. How do they have any advantage concerning these problems over standard naturalists such as Fodor and Lewis who do not recognize cognitive phenomenology? True, they believe that some of the relevant content-grounding naturalistic properties are identical with non-sensory 
phenomenal properties, while standard naturalists deny that they have any special "feel." Perhaps it will be said that this gives them an advantage (thanks here to Uriah Kriegel). But how could this identity claim possibly help them solve these particular problems? What exactly are their solutions? Their acceptance of this identity claim does not mean that they believe that there are more facts out there in the world than those recognized by standard naturalists like Fodor and Lewis. Both sides agree that the only facts out there are the naturalistic facts: facts about functional role, inferential role, tracking, biological function, and so on. So they have exactly the same basic materials to work with. Therefore, if there are solutions to the aforementioned metaphysical problems about content determination compatible with functional CP-determination, those very same solutions are also compatible (mutatis mutandis) with standard naturalism.

Since I can think of no plausible reductive theory of cognitive phenomenology consistent with the things proponents of CP-determination have said, I provisionally conclude that they must accept primitivist CP-determination. Indeed, the passages from Horgan and Tienson and Strawson quoted in $§ 1$ already suggest some kind of "primitivist" view of cognitive phenomenology and intentionality.

Primitivist $\mathrm{CP}$-determination comes in two possible versions. According to a quite extreme version, there is no real definition of a cognitive phenomenal property. In other words, there is no (a priori or a posteriori) answer, in neural or functional or other terms, to the question: what is it to have a given cognitive phenomenal property? In this sense, cognitive phenomenal properties are utterly simple, just as G. E. Moore said goodness is utterly simple. Yet they somehow "ground" determinate belief and desire properties, in accordance with CP-determination. For instance, it is just a brute fact that, if you have a certain utterly simple, unstructured cognitive phenomenal property, you stand in the belief relation to a plus-content, as opposed to a bent, quus-like content. According to another version of primitivist CP-determination, there is a partial answer to the question: what is it to have a particular cognitive phenomenal property? The idea is that having a particular cognitive phenomenal property simply consists in (and so trivially determines) occurrently standing in a particular intentional relation to a particular narrow content. So cognitive phenomenal properties have a relational structure. Of course this identity view would nicely explain the tight relationship that is supposed to obtain between cognitive phenomenology and intentionality. It would explain why it is necessary that if you "change either the attitude-type (believing, desiring, wondering, hoping, etc.) or the particular [narrow] intentional content" then "the phenomenal character thereby changes too" (Horgan and Tienson 2002: 522). ${ }^{13}$ What makes the view I have in mind primitivist is that it adds that there 
is in turn no reductive account of our phenomenally constituted intentional relations toward narrow contents. For instance, there is no answer to the question: what is it for you to occurrently believe that two plus two equals four, as opposed to two quus two equals four? This kind of "constitutive" question cannot be answered by appealing to functional role or anything else. This view of cognitive phenomenal properties is analogous to non-reductive intentionalism about sensory phenomenal properties (Chalmers 2006; Pautz 2006, 2010a).

Now I can finally state my "danglers" argument, which targets primitivist $\mathrm{CP}$-determination. Let $P$ be the phenomenal property which allegedly determines (perhaps just is) your occurrently believing that two plus two equals four, as opposed to two quus two equals four. According to primitivist $\mathrm{CP}$-determination, $P$ is not a physical property, at least in a narrow sense where physical properties just include mainstream physical properties like neural properties, functional properties, tracking properties, and so on. Yet even on this view your having this primitive cognitive phenomenal property is not a fluke; it is in some sense determined by one of your mainstream physical properties. Thus Strawson (2010: note 54) speculates that cognitive phenomenal properties are dependent on neural properties instantiated somewhere near the sensory regions of the brain. Alternatively, perhaps your having $P$ is connected to (but distinct from) your having a more complex functional property involving your inferential dispositions. In any case, there is a true conditional of the form: necessarily, if any individual has physical property $F$, then that individual has distinct primitive cognitive phenomenal property $P$, which in turn determines (and perhaps just is) his occurrently believing the content two plus two equals four as opposed to the content two quus two equals four. These conditionals link the physical properties of individuals with their determinately believing (or desiring or wondering) some narrow contents rather than others.

Now, according to any version of primitivist CP-determination, these conditionals simply admit of no explanation. On one version, they are merely nomically necessary. They are fundamental laws of nature, dangling from the body of fundamental physical laws of nature. For instance, maybe there is a basic law linking some neural state $M$ with a plus-phenomenology and a certain plus-content (for example, two plus two equals four), rather than a quus-phenomenology and a quus-content (two quus two equals four). This amounts to dualism: there are possible zombie worlds, in which everyone is physically the same but no one has the relevant special phenomenal and intentional properties. On another possible version of primitivist $\mathrm{CP}$-determination, the conditionals linking physical conditions with distinct intentional conditions are brute metaphysical necessities. What I mean by calling them "brute" is not that they are not a priori. I mean that they cannot be derived from more basic modal truths (roughly along the lines of Dorr 2007). In that sense, they "dangle from" the rest of the body of 
modal truths. In this version, primitivist CP-determination amounts to what I have called primitivist physicalism (Pautz 2010a; see also Horgan 2010). Note that this view is exactly like dualism concerning what there is. It only differs from dualism only modally, since like physicalism it entails that zombie worlds are metaphysically impossible.

Now we all must admit some brute nomic and metaphysical necessities: the fundamental laws of nature, the truths of logic, maybe certain non-logical metaphysical principles. However, we have general Occamist reasons to keep them to a minimum. The trouble with primitivism about cognitive intentionality is that it solves the determinacy problems due to Quine and Kripkenstein at the cost of obnoxiously multiplying the stock of basic modal truths. This is not a knockdown argument; but it gives us a strong reason to disbelieve the view. ${ }^{14}$

My point here should be put as a dilemma. Either proponents of $\mathrm{CP}$-determination say that cognitive phenomenal properties are identical with mainstream physical or functional properties, or else they accept primitivism. If they accept the first horn (Kriegel 2011: chap. 2 expresses sympathy), then they might avoid "danglers," because then they would have a respectable reductive view. But then they are in effect accepting one or another of the familiar attempts to "naturalize" intentionality (Fodor, Dretske, Lewis, etc.). They are only adding that the physical-functional properties that determine content have a non-sensory "feel." This does not help them solve the standard problems of detail due to Kripkenstein and Quine and others. ${ }^{15}$ If, on the other hand, they take the second "primitivist" horn, then their solution to these problems is not novel: it is just the primitivist solution, which has been on the table from the start (Quine 1960: 221). They are just adding that the primitive intentional properties have a non-sensory feel. Moreover, they face the "danglers" argument.

\subsection{The Separation Argument}

My remaining arguments against $\mathrm{CP}$-determination-the "separation argument" and two more arguments to follow-have a common form.

To begin with, let me introduce the notion of sensory-functional conditions. These are conditions concerning your actual or possible sensory experiences. They include your actual perceptual and bodily experiences, sensory images, your experiences of inner speech, and transitions among sentences in inner speech. They include your experiences of behaving in the world. They also include causal and dispositional conditions about your sensory experiences. Thus, supposing you believe that there is food in the fridge, they include your disposition to form an image of food in the fridge, your disposition to look in the cupboard should you not see food in the fridge, and so on. 
Now built into CP-determination is a certain irreducibility thesis. This is the thesis that cognitive phenomenal properties, and hence some belief and desire properties, are distinct from all sensory properties, forming an autonomous level of mental reality. Indeed, following standard practice, I have stipulated that "cognitive phenomenal properties," if such there be, are distinct from sensory properties. Now irreducibility typically goes with modal independence. So the CP-determination thesis entails that cognitive phenomenal properties, and hence some belief and desire properties, are totally modally independent of all sensory properties (Chalmers 2008). So they ought to be totally modally independent of sensory-functional conditions, for those are just conditions involving patterns in the instantiation of sensory properties. All cognitive phenomenal properties, and hence some belief and desire properties, ought to be combinable with any set of sensory-functional conditions. Consider an analogy: since auditory qualia are distinct from visual qualia, they can be combined with any series of visual qualia.

What my next three arguments have in common is that they are supposed to show that it is not true that cognitive phenomenal properties, and hence some belief and desire properties, are completely modally independent of sensory-functional conditions. I will ask whether we can make sense of three types of scenarios in which cognitive phenomenal properties float free from sensory-functional conditions. I will argue that we cannot make sense of these scenarios.

My first argument, the separation argument, generalizes my "separation argument" against biological CP-determination (§3.1) to any version of $\mathrm{CP}$-determination. Consider an example. According to the $\mathrm{CP}$-determination thesis defended by Horgan and Tienson, there is a cognitive phenomenal property $P$ that metaphysically necessitates occurrently believing the narrow, de se content there is a picture on the wall behind one. Now, in the actual case, $P$ is associated with certain sensory-functional conditions: for instance, having the sentence "there is a picture on the wall behind me" run through one's interior monologue, and imagining (or being disposed to imagine) a picture on the wall behind one.

The first step of my separation argument asserts that, if there is such a property as $P$ distinct from all sensory properties, then there should be possible "separation cases" in which it is associated with a completely different set of sensory-functional conditions than those with which it is actually associated. In one such case, while Charlie has $P$, the sentence "there is a clock on the wall" runs through his interior monologue (where Charlie manifests understanding this sentence just as we do), he is disposed to form a sensory image of a clock on a wall, and in general has sensory experiences of behaving exactly as if there is a clock on the wall behind him (for example, if he were to experience someone asking for the time, he would experience himself turning around and looking at the wall). 
The second step of my separation argument asserts that, in this case, even though by stipulation Charlie has $P$, he does not occurrently believe that there is a picture on the wall behind him, contrary to Horgan and Tienson's $\mathrm{CP}$-determination thesis. The clock-appropriate sensory-functional conditions present in the case are incompatible with his having this occurrent belief. ${ }^{16}$ In general, for any belief and desire, some sensory-functional conditions are a priori incompatible with having that belief or desire. ${ }^{17}$ In this sense, there are sensory-functional constraints on belief and desire..$^{18}$

Consider a second separation case. Let $P$ be the cognitive phenomenal property which, according to proponents of CP-determination like Strawson, metaphysically necessitates occurrently believing the narrow content two plus two equals four, thus solving the Kripkenstein problem. Again, my separation argument against CP-determination has two steps. First, if there is such a non-sensory property as $P$, then a baby (say) presumably might have $P$ for a few seconds while otherwise remaining the same. This might involve temporarily modifying its neural state in the "cognitive phenomenology center" of its brain (Strawson 2010: note 54) while leaving everything else the same; but I see no reason that it should not be metaphysically possible. Second, even though the baby has cognitive phenomenal property $P$, it does not occurrently think that two plus two equals four, contrary to CP-determination. That would require that it have certain arithmetical concepts (for example, plus), which in turn would require that it have certain arithmetical abilities (for example, the ability to count). But by stipulation it lacks these abilities. In general, the sensory-functional conditions present (or rather absent) in the case are incompatible with the baby's having the belief that two plus two equals four. ${ }^{19}$

Here is a final separation case. First consider an actual person, Elmer. As we saw in $\$ 1$, according to Horgan and Tienson, when an ordinary person like Elmer says "There's a rabbit" and then "There's an undetached rabbit-part," he enjoys different cognitive phenomenal properties, and this somehow solves Quine's (1960) inscrutability problem. Call them $R$ and $U$, respectively. Now consider an altered cognitive qualia case where these cognitive phenomenal properties are everywhere swapped with one another, but the sensory-functional facts remain exactly the same. I cannot imagine this and so am skeptical of the very existence of these properties; but if Horgan and Tienson are right that there are such cognitive phenomenal properties distinct from sensory properties, the case should be possible. Further, given their commitment to CP-determination, they must say that, in this counterfactual case, when Elmer says "there's a rabbit," he is really thinking there is an undetached rabbit-part, because he has cognitive phenomenal property $U$ instead of $R$. There are radical intentional differences between the actual case and this case, even though they are completely identical in all sensory and functional respects. This is absurd: by stipulation, in this case as in the actual case, Elmer 
visually focuses on the whole rabbit, he insists "I am thinking about the rabbit, not just a rabbit-part," and the use-properties of his sentences are exactly as they are in the actual case. ${ }^{20}$

Now Siewert (1998: 285) at least addresses a case similar to one of my cases, the baby case. He simply asserts that the case is impossible, saying that he accepts "holism" about cognitive phenomenal properties and rejects "atomism." He does not address cases like my Charlie case or my Elmer case in which cognitive phenomenal properties are associated with different sensory-functional conditions than those with which they are in fact associated. But he might just declare that they too are impossible. In general, proponents of CP-determination (Graham, Horgan, and Tienson, Pitt, Strawson) might say that, since there are necessary sensory-functional constraints on belief and desire, and since cognitive phenomenal properties determine belief and desire, there are necessary sensory-functional constraints on cognitive phenomenal properties.

But this is not enough. Remember: I gave an argument for claiming that, if there are cognitive phenomenal properties, then separation cases are possible. Graham, Horgan, and Tienson as well as Pitt themselves say that cognitive phenomenal properties are distinct from all sensory properties. Given this, they should be totally modally independent of sensory properties. Hence they should be modally independent of sensory-functional conditions, since these simply concern the pattern of instantiation of sensory properties. If proponents of $\mathrm{CP}$-determination say that my separation cases are not possible, they need to answer this argument. When something is impossible, we generally expect an explanation for why it is impossible.

Here is one response. According to David Lewis's theory of belief, occurrently believing that two plus two equals four is a complex functional property $L$ involving relations to experiences, other beliefs, and behavior. This view explains why belief properties are holistic and not atomistic, so that a baby (for instance) cannot have arithmetical beliefs. It explains why there are necessary sensory-functional constraints on belief and desire. To explain why separation cases are not possible, the proponent of CP-determination might apply the same model to cognitive phenomenal properties. Thus he might simply identify the cognitive phenomenal property $P$ (which allegedly determines believing two plus two equals four) with the Lewisian functional property $L$. In general, cognitive phenomenal properties reduce to functional properties, he might say. This would explain why cognitive phenomenal properties are holistic and not atomistic (why there are necessary sensory-functional constraints on having such properties), something Siewert asserts without explaining. It would explain why my separation cases are not possible for cognitive phenomenal properties, thus answering my separation argument against CP-determination.

But now CP-determination has become functional CP-determination. It is now just functionalism about intentionality. As we saw in $§ 3.1$, this is not 
compatible with the usual commitments of friends of the phenomenal intentionality program. Indeed, they seem to hold that cognitive phenomenal properties are primitive properties that cannot be reduced to mainstream physical properties of any kind.

Let me suggest a different reply to my separation argument on behalf of proponents of CP-determination. I will introduce the reply by analogy. Swoyer (1982) accepts an interesting view about fundamental physical properties, like masses and charges. According to this view, they do not reduce to clusters of dispositions or functional properties. But they essentially possess certain (second-order) nomic properties and essentially stand in certain nomic relations; these are given by the fundamental physical laws. So they are necessarily connected with certain dispositional and functional properties, and "separation cases" in which they are recombined in ways that violate their nomic profiles are metaphysically impossible. There are unHumean metaphysically necessary connections between distinct existences.

Likewise, proponents of CP-determination might say that cognitive phenomenal properties are distinct from sensory phenomenal properties. But they are necessarily connected with certain sensory-functional conditions. They essentially bear certain systematic relations to various other states and conditions: other cognitive phenomenal properties, behavior or attempts at behavior, mental dispositions and abilities (for example, inferential dispositions and dispositions to form certain images), sensory experiences, and so on. Hence, any given cognitive phenomenal property (realizing a particular belief or desire property) necessarily brings with it a system of states and abilities. This is not because cognitive phenomenal properties reduce to abstract functional properties or clusters of dispositions, as in functional CP-determination. Rather, it is just a brute modal fact, brute in the sense that it cannot be derived from real definitions and logic (Dorr 2007). Hence, under this view, the sensory-functional constraints on belief and desire are just brute modal facts. Call this version of $\mathrm{CP}$-determination systemic CP-determination. Under systemic CP-determination, my separation cases involving cognitive phenomenal properties (Charlie, the baby, Elmer) are impossible. So my separation argument against $\mathrm{CP}$-determination fails at the first step.

But, since we have no reason to accept CP-determination in general ( $\$ 2$ ), we have no reason to accept systemic $\mathrm{CP}$-determination. On the other hand, we have strong reasons to reject it. (i) Previously, we saw that proponents of $\mathrm{CP}$-determination apparently must accept primitivist CP-determination, which requires brute modal principles connecting cognitive phenomenal properties with underlying physical states. Now we have seen that, to accommodate the sensory-functional constraints on belief and desire and avoid my separation argument, they must accept additional brute "systemic" principles connecting cognitive phenomenal properties with other mental conditions 
and background abilities. But we ought to keep brute modal principles to a minimum. ${ }^{21}$ (ii) Presumably, a fundamental physical property might have a determinate functional profile, given by the fundamental laws of nature. But what are the essential functional profiles of cognitive phenomenal properties? For instance, does the cognitive phenomenal property $P$ discussed previously necessitate the disposition to form a visual image of a picture (rather than a clock) on the wall behind one (at least in those with the capacity for visual imagination)? Presumably, there will be a lot of vagueness here. So systemic CP-determinate requires objectionable "vagueness in the world" concerning the fundamental modal facts. ${ }^{22}$

\subsection{Absent Cognitive Qualia Cases}

Before (\$2) I used absent qualia cases to undermine the determinacy and access arguments for CP-determination. Now I will use such cases in arguments against cognitive phenomenology.

My first argument casts doubt on the basic $\mathrm{CP}$-existence thesis and has two steps. The first step asserts that, if there are cognitive phenomenal properties, then cases of the following kind are possible and indeed we should be able to positively imagine them: (i) you have exactly the same sensory properties and functional properties that you have in the actual case, and yet (ii) your phenomenal life is profoundly different from your actual phenomenal life in that you lack the phenomenal properties (namely, cognitive phenomenal properties) you actually enjoy. Indeed, presumably, if the CP-existence thesis is true, and cognitive phenomenal properties form a distinct experiential modality (Strawson 2010: note 54), then there might be among actual humans individuals who lack cognitive qualia, but otherwise have phenomenal lives very similar to normal individuals. Analogy: our auditory phenomenal properties are distinct from our visual phenomenal properties. So there are possible (indeed actual) individuals who see but do not hear.

The second step of the argument is that we cannot positively imagine such cases. Just try. Suppose in the actual case you hear a friend say "Let's go to the bar later" and you quickly form an image of the local bar and follow up with a question as to time. Now try to imagine a case that is completely identical to the actual case in all sensory and functional respects, and yet profoundly phenomenally different in many ways in that you lack the cognitive phenomenal properties that you allegedly actually possess. I honestly cannot do it.

In short, the CP-existence thesis makes testable empirical predictions about what we can imagine. But the predictions are false.

Perhaps the proponent of the CP-existence thesis will reply: just imagine hearing "Let's go to the bar" while not being a speaker of English. But that case would differ in sensory and functional respects from the actual case. If I did not 
understand English my auditory system would not parse the auditory stream "Let's go to the bar" in the same way it actually does. So I would have a different auditory experience. I would also not form a quick image of the local bar. Not understanding what was said, I might also feel stressed. And I would not be disposed to follow up with certain questions. What the proponent of the $\mathrm{CP}$-existence thesis is committed to is the possibility of a case in which all the past and present sensory and functional facts are held constant (the very same auditory experiences, the same imagery, the very same feelings, and so on), and yet my phenomenal life is profoundly different from my actual phenomenal life in myriad ways. It is this I cannot imagine.

Galen Strawson suggested another reply to me (in discussion): that in the hypothetical case I would just be very bored. But, since in this case I would be a sensory-functional duplicate of my actual self, I do not think I would be bored. More importantly, if we actually have cognitive phenomenal properties, then the absent cognitive qualia case would differ from the actual case in many ways: each and every cognitive phenomenal property I allegedly actually possess would in this case be "subtracted out." To simply say that I would be bored simply does not enable me to imagine the myriad ways in which this case would differ from the actual case.

Maybe the defender of cognitive phenomenology could insist that this case is possible, even if I cannot imagine it. But why should this be? It is not only possible that my experiential life should differ in myriad ways because I lack all of my actual auditory phenomenal properties while the rest of my phenomenal life is held constant; I can easily imagine this case. So why cannot I easily imagine occupying a phenomenal world different in myriad ways because all of my actual cognitive phenomenal properties are removed, while all of the sensory and functional aspects of my life stay exactly the same? ${ }^{23}$

Now I turn to my second argument involving absent cognitive qualia cases. While my first argument was directed against proponents of the $\mathrm{CP}$-existence thesis, my second argument is directed against what we might call the necessity thesis: non-sensory cognitive and conative qualia are necessary in order to have the level of content determinacy we actually enjoy. We have seen that Horgan and Tienson rely on this thesis in their determinacy argument for CP-determination (it corresponds to premise 3 of that argument). Strawson (in the quote in $§ 1$ ) also says that cognitive qualia are necessary to solving the Kripkenstein problem.

Let's focus on an example. Suppose that in the actual case while hunting Elmer has a visual experience of a rabbit and has the sensory phenomenology of attending to the whole rabbit, as opposed to a rabbit part. He says, "Lo, a rabbit." He also has hunger pangs and imagines having rabbit for dinner. He is disposed to behave exactly as if he believes that a rabbit is present and desires to have it for dinner. 
Next consider an absent cognitive qualia case in which the entire human population is identical to the actual population in all sensory and functional respects, but no one possesses any non-sensory cognitive and conative phenomenal properties. ${ }^{24}$ So in this case Elmer is just as I have described him to be in the actual case, only he lacks any cognitive and conative qualia.

Now, arguably, in the absent cognitive qualia case as well as in the actual case, Elmer has some kind of rabbit beliefs and desires (see $§ 2.2$ for arguments that individuals in absent cognitive qualia cases are not "cognitive zombies"). The proponent of the necessity thesis need not say otherwise. What he must say is only that in the absent cognitive qualia case Elmer's rabbit beliefs and desires are much more indeterminate in content than they are in the actual case. In particular, given what they say in the passage quoted in $\S 1$, Graham, Horgan, and Tienson are committed to saying that in the actual case Elmer determinately believes that a rabbit is present and desires to have a rabbit for dinner, whereas in the absent cognitive qualia case it is indeterminate whether Elmer's belief and desire are about rabbits as opposed to undetached rabbit parts. So there is a difference in intentional facts across the cases.

This case shows that the necessity thesis violates sensory-functional supervenience: the thesis that the total intentional facts about a population supervene on the total sensory and (wide and narrow) functional facts about that population.

My argument against the necessity thesis is now this. In the absent cognitive qualia case as in the actual case, Elmer enjoys the sensory phenomenology of focusing on the whole rabbit (not just a part), he is disposed to respond to Quinean indeterminacy arguments by insisting that he has beliefs and desires about "rabbits" rather than "undetached rabbit parts," the use-properties of his sentences are exactly the same, and so on. All the first-person and third-person evidence suggests that across these cases his belief and desire enjoy the same level of determinacy, contrary to the necessity thesis.

Likewise, in an absent cognitive qualia case identical to the actual case in all functional and sensory respects (including experiences of counting objects and so on), all the first-person and third-person evidence suggest that our arithmetical beliefs have the same level of content determinacy that they have in the actual case. Therefore, contrary to Strawson, cognitive qualia are not necessary to answering the Kripkenstein problem.

This supports sensory-functional supervenience: the total intentional facts about a population supervene on the total sensory and (wide and narrow) functional facts about that population, without any need for cognitive qualia.

\subsection{Disembodied Cognitive Qualia Cases}

Finally, I have two related arguments against cognitive phenomenology involving what I shall call "disembodied cognitive qualia cases." 
My first argument casts doubt on the CP-existence thesis and has two steps. If there are cognitive qualia, then in the actual world they are embodied in the sense that they are accompanied by sensory properties, including experiences of having a body and acting on the world. The first step of my argument asserts that, if there are cognitive phenomenal properties distinct from all sensory properties, then disembodied cognitive qualia cases ought to be possible and indeed we should be able to positively imagine them. In such a case, we allegedly have a rich phenomenal life that overlaps with our actual phenomenal life because we have all the same cognitive phenomenal properties we have in the actual world; but our cognitive phenomenal properties are "disembodied" in the sense that they are not accompanied by any sensory properties. In other words, we have no visual experiences (including no experiences of having a body or engaging in apparent behaviors), auditory experiences, no mental imagery, no "inner speech," and so on. Consider an analogy: auditory qualia are distinct from other kinds of qualia. So we can imagine cases in which such qualia occur in the absence of all other sorts of qualia. ${ }^{25}$

The second step of my disembodied cognitive qualia argument against the $\mathrm{CP}$-existence thesis is that we cannot positively imagine such a case. At least I cannot. Just try. If the CP-existence thesis is true, then in such a case we have a rich phenomenal life that overlaps with our actual phenomenal life, only it is totally non-sensory. But what would it be like? Can you imagine this overlapping phenomenology? If you try to imagine what it would be like, you might imagine seeing all black, having an experience of inner speech ("nothing much is happening"), and so on. But then you will not be imagining a case in which you have cognitive phenomenal properties but no sensory properties. So the $\mathrm{CP}$-existence thesis makes a false empirical predication about what we can imagine.

In reply, the proponent of the $\mathrm{CP}$-existence thesis might say that such cases are possible, but that for some reason we cannot positively imagine them. But why not? When it comes to other sorts of qualia, we can easily imagine cases in which they occur in the absence of distinct kinds of qualia: for instance, we can imagine having only auditory qualia.

Now I turn to my second argument involving disembodied cognitive qualia cases. While my first argument was directed against the CP-existence thesis, my second argument is directed against the CP-determination thesis. Let Nemo be someone who enjoys a rich series of cognitive phenomenal properties of the kind we actually undergo but who has no sensory phenomenal properties at all. (For the sake of argument, let us just grant that the case is possible, contrary to my first argument.) Now, according to CP-determination, Nemo's having such a rich series of cognitive phenomenal properties alone determines (perhaps just consists in) his having a series of our actual sophisticated narrow beliefs and desires: for instance, the belief that two plus two equals four (Strawson), the belief that a picture is hanging on the wall behind him (Horgan and Tienson), and so on. Hence, according to CP-determination, Nemo has a 
rich series of occurrent narrow beliefs and desires, even though he has never had any sensory experiences whatever.

But this can be ruled out a priori. Even if Siewert (1998: 277) is right that there are occasional cases of simple, purely non-sensory conscious thoughts in us (I would deny even that), the extreme case of Nemo is impossible. Like the baby discussed earlier, Nemo does not satisfy the a priori sensory-functional constraints on belief and desire. He has never had any visual or other experiences of walls or pictures or spatial properties (like being behind), or sets of two or four objects. He does not use a language like English, or even have experiences of using a language like English. He does not have any dispositions to engage in physical behavior. In fact, he does not have any experiences of behaving in the world (for example, counting or adding). He does not even have any experiences remotely like these experiences, even if he has "cognitive experiences." Intuitively, all this means that we cannot credit him with the belief that two plus two equals four, the belief that a picture is hanging on the wall that is behind him, and so on. Hence, even if the CP-existence thesis is true, consideration of disembodied cognitive qualia cases show that the $\mathrm{CP}$-determination thesis is false.

The proponent of $\mathrm{CP}$-determination can avoid this argument only by accepting what I called systemic CP-determination. The idea would be that, even though cognitive phenomenal properties are distinct from all sensory phenomenal properties, they are somehow necessarily connected with sensory phenomenal properties, so that entirely "disembodied cognitive qualia" cases are impossible. But, as I said, there is no reason to accept this view and it requires brute modal connections. It is a bit like saying that, even though auditory qualia are distinct from visual qualia, they are necessarily connected with visual qualia.

In sum, the CP-determination thesis holds that cognitive phenomenal properties, and hence some belief and desire properties, are entirely distinct from sensory properties. They form a distinct level of mental reality. But then they ought to be totally modally independent from sensory-functional conditions. But consideration of separation cases, altered cognitive qualia, absent cognitive qualia, and disembodied cognitive qualia suggest that this is not so. Indeed, these cases support sensory-functional supervenience: the total intentional facts about a population supervene on the total sensory and (wide and narrow) functional facts about that population, without any need for cognitive phenomenology. I will now sketch a view of this kind.

\section{An Alternative: Phenomenal Functionalism}

The CP-determination thesis does not represent the only way of developing the plausible, broadly empiricist thought that phenomenology grounds mental content. 
I will now sketch a modified version of David Lewis's influential functionalist theory of intentionality, which I call phenomenal functionalism. It entails that sensory phenomenology grounds all determinate intentionality. I will not attempt to argue for Lewis's holistic, functionalist approach; Lewis and others have done so and the virtues of a holistic approach to belief and desire should be clear from the preceding discussion. Instead, after briefly stating Lewis's own functionalism, I will raise an overlooked problem for it involving the notion of sensory evidence. Then I will explain phenomenal functionalism and how it solves the problem. Finally, I will explain how it accommodates the main ideas of the phenomenal intentionality program while avoiding the problems I have raised for $\mathrm{CP}$-determination.

Roughly, according to Lewis's own a priori functionalism (1974: 120), an individual has an (occurrent or standing) intentional state (for example, belief or desire) with content $p$ iff it is part of the best interpretation (or all of the interpretations tied for best) that the individual has that intentional state. Lewis holds that the best interpretation is an objective notion: it is the assignment of intentional states that best satisfies a handful of general principles, given the functional facts about the individual and others of his kind. The principles are a priori truths about intentional states drawn from folk psychology. ${ }^{26}$

One principle is the behavior-rationalization principle: all else being equal, an individual tends to have beliefs and desires that make his behavior largely rational. But this cannot alone determine a reasonable best interpretation. Suppose Karl is in front of a round thing and reaches for it. One interpretation is that he wants a round thing, believes that a round thing is before him, and so believes that by reaching he will get it. Another, deviant interpretation is that he has a basic desire for a saucer of mud, believes that one is before him, and so believes that by reaching he will get it.

Lewis therefore invokes a second principle, the humanity (or "charity") principle. It has two parts. First, some basic beliefs and desires are objectively reasonable simpliciter, and people tend to have these. Second, some beliefs (and perhaps even some desires) are objectively reasonable, given one's history of sensory experiences and evidence; and people tend to have these. This does not mean that a subject's beliefs or experiences must be largely accurate: the beliefs of a brain in a vat are reasonable but false. ${ }^{27}$ Now return to Karl. Given that Karl is having an experience as of a round thing, the belief that there is a round thing before him is more reasonable than the belief that a saucer of mud is before him. And a basic desire for a saucer of mud would be unreasonable. So the humanity constraint will favor the first interpretation mentioned over the second, deviant interpretation.

Indeed, Lewis relies on the humanity principle to rule out all deviant interpretations of belief and desire compatible with the behavior-rationalization principle. For instance, given the humanity principle, Lewis could easily rule 
out Williams's (2007) recent deviant global arithmetical reinterpretation of all thought and language (even perceptual reports like "that is square"), by noting that arithmetical beliefs are typically evidentially unrelated our perceptual experiences and other available evidence. ${ }^{28}$ Using the humanity principle, Lewis can also rule out Kripke's more local deviant interpretation of our arithmetical thought, involving the "quus" function. For Lewis explicitly says that his preeminent humanity principle concerning reasonable belief entails as a special case his much-discussed "naturalness principle," which favors natural contents over unnatural ones. ${ }^{29}$ For instance, given our history of evidence, it is more reasonable to believe that all emeralds are blue than it is to believe that all emeralds are grue. In the same way, the humanity principle favors the assignment of more natural plus-contents over unnatural quus-contents. Thus the Kripkenstein puzzle is solved without "cognitive phenomenology." 30

Now for the serious overlooked problem for Lewis's view, which I will call the problem of evidence. Given Karl's rich history of evidence, the humanity principle helps to rule out deviant interpretations. But what determines his evidence? At one point Lewis (1974: 112) speaks of "Karl's life history of evidence according to [the physical facts about him]," suggesting that his evidence is simply part of the basic physical facts about Karl described in non-mental, non-intentional terms. But this is not true. Although there are different conceptions of evidence, Karl's evidence clearly necessarily depends somehow on his history of experiences and their phenomenal characters. Further, there is strong reason to accept intentionalism about experience, according to which their phenomenal characters are determined by their very detailed intentional contents (Chalmers 2004; Pautz 2010c; Tye 2000). Thus the problem of evidence becomes an extremely difficult special case of the problem of intentionality. We might call it the problem of sensory intentionality. This is one element of the hard problem of consciousness. Now, since Lewis is physicalist and a global functionalist who applies his functionalism to all intentional states, in order to solve this problem he needs additional constitutive principles that go from the purely physical facts about Karl to the rich contents of his experiences. His behavior-rationalization principle and his humanity principle evidently only apply to beliefs and desires.

Lewis never explicitly addresses the problem of evidence, that is, the problem of sensory intentionality. However, he does say something that suggests what his solution might be: "A state typically caused by round things before the eyes is a good candidate for interpretation as the visual experience of confronting something round" $(1983,374)$. Lewis also holds that an experience as of a red thing is a state that is caused by the color in fact possessed by pillar-boxes and other standard red things. This suggests a simple causal principle: very roughly, if, in the relevant population, state $S$ would be caused by something's being $F$, 
in so-and-so range of actual and counterfactual cases, then $S$ is an experience with the content that something is $F$ is present.

The idea is that suitable causal connections to the world pin down the rich contents of Karl's experiences and hence (given intentionalism) what his experiences are like and what evidence is available to him. In turn, by the humanity constraint, Karl's experiential evidence plays a crucial role in pinning down the contents of his beliefs and desires and ultimately language, by ruling out "deviant interpretations." Thus, causal connections to the world very indirectly help fix the contents of his beliefs and desires. ${ }^{31}$

It is worth mentioning that Lewis's appeal to the actual and potential causes of a state is quite compatible with his well-known belief in narrow content and his intuitive motivation for it (pace Stalnaker 2004: 211). Lewis explicitly says that, according to his conception of narrow content, it is not wholly intrinsic. For Lewis, narrow content is just content that is intuitively shared by individuals (for example, you and your Twin Earth duplicate) whose states are typically caused by the same external states and typically cause the same behavior across a range of actual and possible cases (1994: 425). Even if causal relations to the world determine content, it can be narrow in his very weak sense (Braddon-Mitchell and Jackson 2007: 240).

However my view is that the causal solution to the problem of sensory intentionality fails, for two reasons. First, the simple causal principle is too simple. The problems are the usual ones for reductive psychosemantic theories: the disjunction problem, the depth (distance) problem, and other problems of detail. Further, as stated, the simple causal principle entails that all states that track the environment are experiences. This is wrong: Karl has perceptual beliefs and various sub-personal states that track the environment, but they are not experiences. These problems are especially serious for the a priori functionalist. You might think that, to solve these problems, he could just propose a much more sophisticated causal principle, appealing to things like asymmetric dependence, biologically normal conditions, and cognitive accessibility. The trouble is that such a principle would be far too recherché to be something that the folk implicitly know a priori. In fact, no such principle could be a priori for the simple reason that we evidently cannot a priori deduce what experiences Karl has merely from the causal and functional facts about him.

My second problem for causal theories of sensory intentionality goes deeper. According to any causal theory, the content of experience, and hence (given intentionalism) the phenomenology of experience, can only be narrow in Lewis's very weak sense: it is shared by duplicates whose states would be typically caused, in the relevant populations, by the same external conditions. But I agree with friends of the phenomenal intentionality program that we should accept some stronger version of phenomenal internalism. The only difference is that, while their arguments are based on dubious intuitions about brains-in-vats (Horgan, 
Tienson, and Graham 2004), mine are firmly rooted in psychophysics and neuroscience. Since the phenomenal character of experience, and hence the content of experience, is internally determined in a strong sense, all causal theories of sensory content like Lewis's are non-starters, even setting aside problems of detail. Indeed, elsewhere I have argued that none of our standard models for reducing intentionality apply to sensory intentionality (see notes 5 and 11).

But while Lewis's ambitious reductive functionalism may fail because it does not apply to the hard case of sensory intentionality, a less ambitious non-reductive version I call phenomenal functionalism may have some promise.

Phenomenal functionalism gives up on the task of providing a functionalist or other reductive account of sensory experience and its intentionality. Here it takes an anti-reductive view, according to which experiences are irreducible intentional states. The anti-reductionist approach could take any of a variety of forms (Alston 1999; Johnston 2007; Levine forthcoming). My own view, non-reductive intentionalism goes as follows (Pautz 2006, 2010a; Chalmers 2006). All experience (with the possible exception of undirected moods) is essentially intentional. For instance, Karl's having an experience with the distinctive phenomenology of seeing a tomato is just a matter of standing in a special "experiential" intentional relation to a detailed intentional content involving simple perceptible properties like colors and shapes. I call this relation the "conscious-of relation." (I do not mean we are literally conscious of contents, which are abstract objects.) What makes the view non-reductive is that it also holds that this relation is irreducible. Although what contents we are conscious of in some sense supervene on physical conditions (on my internalist view, internal physical conditions), the conscious-of relation is not identifiable with a relation characterizable in non-phenomenal, physical terms (for example, a causal or tracking relation).

Phenomenal functionalism combines anti-reductionism about Karl's sensory experiences with a functionalist theory of all of Karl's intentional states other than his sensory experiences, for instance his occurrent and standing beliefs and desires. In particular, Karl has the belief or desire that $p$ iff it is part of "best interpretation" that the agent believes or desires that $p$. Here the best interpretation is the one that best satisfies the a priori principles about beliefs and desires, given two sorts of facts about Karl: (i) his history of experiences, which according to non-reductive intentionalism are themselves fundamental intentional states; and (ii) the wide and narrow functional facts about Karl and others of his kind. The wide functional facts help determine the "wide" contents of his beliefs and desires. Thus, while Lewis's functionalism is global, phenomenal functionalism is local, applying only to non-sensory intentional states. Since it takes sensory experiences to be irreducible intentional states, it agrees with Quine (1960: 221) that determinate intentionality is not reducible all the way down to third-person, physical facts. 
On phenomenal functionalism, when it comes to the problem of intentionality, we start with a giant leg up, because Karl's experiences, with their determinate world-directed intentionality, are among the fundamental facts about Karl. Karl's experiences of the world, which determine his history of evidence, are anchor points that help to determine, via the humanity constraint, the contents of his downstream beliefs and desires and ultimately language, by ruling out deviant interpretations. Thus the present local functionalist theory solves the problem of evidence that plagues Lewis's global functionalist theory. ${ }^{32}$

Phenomenal functionalism should be attractive to friends of the phenomenal intentionality program for several reasons.

(i) Phenomenal functionalism avoids the three main problems I raised for CP-determination. First, it does not require extra laws or "danglers" connecting the physical facts about an agent like Karl with his "cognitive qualia" and thereby his beliefs and desires. The picture is that the physical facts about Karl a posteriori determine his irreducible sensory-intentional states. Then, his irreducible sensory-intentional states, together with the functional facts about him, are enough to a priori determine his beliefs and desires, given general constitutive principles about belief and desire that we must all accept. Second, phenomenal functionalism accommodates and explains the necessary sensory-functional constraints on belief and desire: they follow from the real definition of the belief relation and desire relation in terms of the "best interpretation," given the functional and sensory facts about an agent. Third, it accommodates the plausible thesis of sensory-functional supervenience: the total intentional facts about a population supervene on the total sensory and functional facts about that population.

(ii) Phenomenal functionalism is also compatible with the claim of proponents of the phenomenal intentionality program that much intentionality supervenes on phenomenology alone. To illustrate, now suppose that Karl is a brain in a vat. He has an (illusory) experience as of a round thing. He does not exhibit physical bodily movements. But he attempts to behave as if a round thing is present, and he has experiences as of so behaving. Hence, by the humanity constraint and the behavior-rationalization principle and the other constitutive principles, he counts as having the (false) occurrent belief that a round thing is present. Indeed, maybe "round" in Karl's language gets its content directly from the content of his (hallucinatory) experiences, by way of his accepting something like "round is that shape," while demonstrating an uninstantiated shape property presented by his experience (see Speaks 2011 for an interesting discussion). And maybe the sentence " $2+2=4$ " in Karl's language gets a certain arithmetical content, thanks to its use and "inferential role" as well as considerations of naturalness. And maybe Karl counts as occur- 
rently believing this content, on a certain occasion, by virtue of accepting and understanding this sentence. ${ }^{33}$

On my view, contrary to proponents of CP-determination ( $\$ 1$, there is no non-sensory phenomenal property that is alone necessarily sufficient for believing that two plus two equals four, or that there is a picture on the wall behind one. Rather, the contents of beliefs and desires are always determined by (i) a cluster of actual and dispositional facts about his past and present sensory experiences (including what sentences he accepts and their patterns of use), and (ii) his links to the environment (if such there be).

(iii) Finally, phenomenal functionalism entails the following version of the core thesis of the phenomenal intentionality program that phenomenology is the source of all intentionality: necessarily, if a creature has never had the capacity for experiences (and does not belong to a community with such a capacity), it does not determinately stand in the belief or desire relation to particular contents (as I take it that we at least sometimes do). Phenomenology is at least the source of all determinate intentionality. To see this, imagine a community of zombies who have no experiences but who otherwise resemble us as much as possible. According to phenomenal functionalism, since the zombies have no experiential evidence, the all-important humanity principle cannot kick in to make it the case that deviant interpretations are mistaken. So, if we allow that zombies have beliefs at all, there is always massive indeterminacy concerning what their contents are. Many assert that phenomenology is the source of determinate intentionality; phenomenal functionalism explains why this is so. ${ }^{34}$

I find the source thesis to be independently plausible. Here is an argument. An ideal interpreter given only the fundamental, third-person physical facts about a zombie that entirely lacks sensory experiences would not be able to deduce that they have beliefs and desires that determinately possess some contents and not others. Since the zombie lacks a rich phenomenal life, the ideal interpreter would have no way of ruling out "deviant interpretations." I think that this epistemic gap provides some evidence that any such insentient system in fact has no determinate beliefs and desires. ${ }^{35}$ By contrast, if an ideal interpreter had access to the much richer set of basic facts concerning a sentient creature like Karl (including his first-person sensory experiences together with their rich, determinate intentional contents), he clearly could a priori deduce that he has at least some beliefs and desires with determinate contents.

Phenomenal functionalism, then, has many virtues. However, while it might avoid "the problem of evidence" for Lewis's theory, it does not dodge another overlooked problem for that theory (Pautz 2010a: 55). Like Lewis's theory, it appeals to the nebulous notion of a "best interpretation." Just what makes an interpretation "best"? Until this question is answered, phenomenal functionalism is incomplete. 


\section{Conclusion}

The CP-determination thesis is mistaken. Instead, reflection on various thoughtexperiments suggests that all intentionality is entirely grounded in functional facts as well as sensory and perceptual facts, which on my view are richly intentional and irreducible. The question is how all intentionality is grounded in such facts. I have just sketched an answer to this question, namely phenomenal functionalism, but it is programmatic. David Chalmers, Eric Schwitzgebel, and Jeff Speaks have proposed views in the vicinity. ${ }^{36}$ In any case, I think one thing we have learned is that it is not enough to simply maintain that "phenomenology grounds the contents of occurrent beliefs and desires," as many proponents of CP-determination do. Those of us sympathetic to the phenomenal intentionality program need a systematic theory that tells us how phenomenology grounds content.

\section{Acknowledgments}

I am very grateful to Phillip Goff, Uriah Kriegel, Angela Mendelovici, Galen Strawson, and an anonymous referee for many extremely good and helpful comments.

\section{Notes}

1. In Pautz (2006) and (2010b) I characterize the reductive externalist program in terms of a generic "tracking relation" which can be spelled out in various ways. Kriegel (in his 2011 and in this volume) characterizes the program in similar terms.

2. For phenomenal externalism, see Dretske (1995), Hill (2009), Lycan (2001), and Tye (2000).

3. See Quine (1960) and Kripke (1982). “Kripkenstein" refers to an imaginary proponent of the views that Kripke attributes (some think wrongly) to Wittgenstein.

4. My "phenomenology first" slogan is inspired by Williamson's (2000) "knowledge first" slogan. Williamson holds that knowledge plays a foundational role in the epistemic domain and that it is (at least conceptually) irreducible. Likewise, proponents of the phenomenal intentionality program hold that phenomenology plays a foundational role in the mental domain and appear at least open to the view that it is (ontologically) irreducible.

5. In Pautz (2008), I reject prioritism but defend "integrativism" (in the sensory domain). Chalmers (2008), Mendelovici (2010), and Kriegel (2011: 63) defend the same view. Likewise, in number of papers (2006, 2010a, forthcoming) I reject the standard intuition-based, armchair arguments for phenomenal internalism (for example, Horgan, Tienson, and Graham 2004). But I also defend empirical arguments for a version of phenomenal internalism and against the reductive externalist program. For discussion of the empirical arguments for phenomenal internalism, see Chalmers (2005), Cohen (2009: 81-88), Hill (2012), and Tye and Cutter (2011).

6. I will ignore degrees of belief and desire. (Would advocates of CP-determination say that in some cases these too are constituted by non-sensory feel, rather than functional role?)

7. For this point, see Lewis (1994: 425) and Braddon-Mitchell and Jackson (2007: 240). 
8. See Graham, Horgan, and Tienson (2007, 2009) and Horgan and Graham (2010).

9. The acquaintance model is in any case too simple (Pautz 2011). For instance, it has difficulty explaining why we have immediate introspective justification for believing some complex propositions about our experiences but not others (the "scope problem"); it also cannot explain the graded character of immediate introspective justification.

10. For the argument, see Pautz 2010a: sect. 7. I argue there against internalist reductions of the "consciousness relation" (Horgan, Tienson, and Graham (2004) call it the "acquaintance relation"), but the argument generalizes to internalist reductions intentional relations more generally. Goff (2012) also expresses skepticism about reductive internalist theories of phenomenal intentionality; however, unlike me, he does not develop an argument based on the unavailability of internalist reductions of dyadic intentional relations, which I think is crucial.

11. Even if he is a "non-relationist" about intentional states and indeed rejects the existence of intentional contents and other abstract objects (Kriegel 2011: chap. 3), the proponent of biological CP-determination must recognize the existence of some mental relations, namely mental relations to concrete items such as $x$ has a thought that is accurate with respect to existing concrete scenario $y$. If he accepts that such relations supervene on the totality of physical facts about the world, and if he wants to avoid a primitivist view, he would at least need an account of these relations in purely physical, non-mental terms.

12. For the point that the only kinds of functional properties that might determine intentionality (and hence phenomenal intentionality, if such there be) are non-intrinsic and involve relations to the environment or behavior, see especially Braddon-Mitchell and Jackson (2007: 240). Kriegel (2011: 246) claims that his favored functionalist theory of phenomenal intentionality is compatible with the intrinsicness claim. But since Kriegel (2011: 73) explains phenomenal intentionality in terms of our states having the Dretskean function to indicate various externally instantiated response-dependent properties, and since Dretskean functions always require history (a non-intrinsic affair), this is unclear. See Pautz (2010b: 351ff) for more discussion.

13. For discussion of the identity view, see Pautz (2008: 269), Pitt (2009), Mendelovici (2010), Kriegel (2011: 63). This view entails that slight differences in cognitive phenomenology between individuals (as it might be, between two people who say "Aristotle was smart") would entail that they entertain slightly different "narrow" contents, even if they might entertain the same "wide content" (see Montague 2010 for this point).

14. According to the kind of view I will sketch in $\S 4$, all facts about beliefs and desires reduce to clusters of functional facts and sensory facts, but sensory facts are not in turn reducible to physical-functional facts. So my own view requires physical-sensory danglers: brute bridge principles connecting the physical with the sensory. My hope is that the correlations between the physical and the sensory are systematizable, so that only a handful of physical-sensory danglers will be required. My "simplicity" objection to $\mathrm{CP}$-determination is that it is even more complex: it requires, not only physical-sensory danglers, but a whole slew of physical-cognitive danglers. That is a point against it. As we shall see, I have additional objections to CP-determination, which are independent of my present appeal to simplicity.

15. Indeed, elsewhere (Pautz 2010b: 351ff) I argue that Kriegel's (2011: 176, note 30) particular naturalistic theory of phenomenal intentionality (a higher-order tracking theory, where the tracked properties are response-dependent properties) faces serious problems of detail in addition to the usual problems, such as Kripke's plus-quus problem and Quine's inscrutability problem.

16. The proponent of $\mathrm{CP}$-determination might grant that a wide range of bizarre separation cases involving a given cognitive phenomenal property are possible (not just the Charlie case, but the baby case discussed later), but insist that across these cases it determines the same narrow content. This is what Siewert (2011) calls "the part of what is thought that is fully determined by [cognitive] phenomenal character." The proponent of CP-determination might suggest that my separation argument only shows that this is not a content of the sort proposed by Horgan and Tienson and Strawson that can be 
captured in ordinary language and that involves ordinary concepts like picture or two or plus. (Thanks to David Chalmers and Angela Mendelovici here.) But if he cannot even gesture at some specification of them, we have no reason to believe there are such contents.

17. My claim that there are sensory-functional constraints on belief and desire does not amount to any crude behaviorism or functionalism; for instance, it is obviously quite compatible with the claim that Strawson's (2010) weather watchers could have beliefs and desires.

18. While I think that there are holistic a priori sensory-functional constraints on cognitive intentionality, I do not think that there are holistic a priori functional constraints of any kind on sensory intentionality (or at least those aspects of sensory intentionality fixed by sensory phenomenology). See Pautz (2010c: 271). In my view, this is an important difference between cognitive intentionality and sensory intentionality.

19. Horgan and Tienson in one place (2002: 526) appear to accept qualified CP-determination: necessarily, if an individual has a certain cognitive phenomenal property and "has a sufficiently rich network of actual and possible phenomenal/intentional states," then the individual has a thought with a certain narrow content (for example, there is a picture on the wall, or two plus two equals four). Unfortunately, they do not explain what this means or why they say it. In any case, my Charlie case and my baby case are counterexamples even to qualified CP-determination. For Charlie and the baby do have a rich network of phenomenal/intentional states in addition to the relevant cognitive phenomenal properties (they both have many experiences and thoughts). Yet they do not have the occurrent thoughts which are allegedly necessitated by those cognitive phenomenal properties in the context of a rich network of phenomenal/intentional states.

20. Indeed, if CP-determination is true, then there is a possible world where Elmer's sensory-functional duplicate believes there is a spaceship when he sees a rabbit and says "there is a rabbit," provided then he has the cognitive phenomenal property $S$ that determines that belief. But this intentional difference would be unknowable as all the sensory-functional facts would suggest in this world he believes that a rabbit is present just as he does in the actual world.

21. In reply, the proponent of $\mathrm{CP}$-determination might say that the sensory-functional constraints on cognitive phenomenal properties are not brute. He might say that they follow from the simple fact that having cognitive phenomenal properties amounts to standing in certain intentional relations (occurrently believing or occurrently desiring) to certain contents, together with the fact that there are sensory-functional constraints on standing in such relations to contents. But this just passes the buck. The question then becomes "Why are there sensory-functional constraints on standing in such relations to contents - in other words, why are such intentional relations necessarily constrained by the sensory-functional facts?" Can this be explained by more basic modal truths? (To say that it is "part of their essence" would not be an explanation.)

22. Siewert might offer a different reply to my separation argument (1998: 286). In one formulation of his claim about cognitive phenomenology determining intentionality, it just amounts to the claim that someone who "has, has had, and is disposed to have, experience with phenomenal character indistinguishable from my own" would have many thoughts. But this is compatible with the denial of CP-determination, and indeed with the non-existence of cognitive phenomenology. For Siewert's total phenomenal twin has the same sensory experiences of conducting inferences in inner speech, the same sensory experiences as of his environment, and the same sensory experiences of acting on the world. Maybe it is such clusters of past and future sensory facts, and not his alleged "cognitive phenomenology," which determine the contents of his beliefs and desires (see $§ 4$ ).

23. Terry Horgan tells me that in forthcoming work he (independently) uses absent cognitive qualia cases, but unlike me he uses them to argue for the CP-existence thesis. It is worth mentioning that the allegedly "diaphanous" character of experience cannot explain why we cannot imagine having profoundly different phenomenal lives due merely to the absence of "cognitive experience." After all, our visual experiences are arguably diaphanous in the sense that we cannot have object-awareness of them (Tye 2000: 51-52), but 
this does not prevent us from being able to imagine cases in which they are absent but our other types of experiences are the same. For, as Tye points out, even if we are not aware of experiences in the sense that we do not have object-awareness of them (we cannot attend to our experiences in addition to attending to the objects and properties represented by experiences), we still are certainly quite aware of them in the sense that we effortlessly have fact-awareness to the effect that they are present.

24. Everyone should believe in the possibility of absent cognitive qualia cases when they are understood in this way. If you think we actually fail to possess non-sensory cognitive and conative "qualia" over and above sensory qualia, as I am inclined to do, then you will think that the absent cognitive qualia case is simply the actual case. On the other hand, if you believe we actually possess such "qualia," then you will also say that the absent cognitive qualia case is possible, but that it would differ phenomenally from the actual case in that we would lack qualia we actually enjoy. My argument will be neutral on this issue.

25. By a "disembodied cognitive qualia case," I do not mean a case in which an individual actually has no body or brain. Maybe an individual can have cognitive qualia only if he undergoes the right physical processing in the alleged cognitive qualia center of his brain. Even in this view, if there are cognitive qualia distinct from all sensory qualia, disembodied cognitive qualia cases should be possible in my sense. For there might be a very inactive brain which only ever undergoes activity in the cognitive qualia center but no other neural area. According to proponents of CP-determination, such an individual would have cognitive experiences but no other experiences, including visual experiences of the world or his body. (Compare: someone might only have auditory qualia throughout his lifetime.)

26. In my view, two functionalist theories of mental intentionality can be extracted from Lewis. First, there is the best interpretation account described in the text. It uses only two or three general principles. And it does not necessarily provide functional definitions of our names for the belief and desire relation (or of the infinitely many names of particular beliefs), anymore than Lewis's analogous best system theory of laws of nature provides functional definitions of names for laws. Second, there is the more familiar functional definition account (Lewis 1972: note 13), which does provides such functional definitions, based on a folk theory containing a huge number of specific platitudes (for example, "if someone tastes something bitter, they have the desire to spit it out"). Here I focus on the best interpretation account, because the functional definition account faces serious problems of detail pointed out by Loar (1981: 60). Loar himself (1981: 62) proposes to solve them by explaining the belief relation and the desire relation in terms of functions-in-extension, but I think his proposal fails. (Briefly, there will be infinitely many "bent" functions that satisfy the functional definitions; and the proposal also faces the usual modal problems with trying to explain relations in terms of sets of their actual instances.)

27. See Lewis (1983) and (1994). Lewis clearly would reject a weak subjective Bayesian interpretation of the humanity constraint. Indeed, he thinks objective Bayesianism is built into folk psychology.

28. In a very helpful discussion, Weatherson (ms) independently suggests that Lewis could use his humanity principle to answer Williams (2007).

29. See Lewis (1983: 375) and (1994: 428). Since Lewis derives the naturalness principle concerning mental content from his more general humanity constraint (which has nothing to do with "simplicity"), I do not think Lewis himself could accept Williams's (2007: sect. 2) suggestion of deriving the naturalness principle concerning mental content from a general principle about simplicity as a theoretical virtue used to decide between theories that fit the data equally well.

30. Here I am mainly focused on mental content but Lewis (1992) also appeals to naturalness in his theory of linguistic content in order to rule out "bent grammars." Horgan and Graham (2010) raise an intriguing general objection to Lewis's theory of intentionality: what makes it the case that naturalness enters into the determination of intentionality, 
either in the mental case or the linguistic case? For instance, by virtue of what does naturalness enter into the determination of linguistic reference (or the semantic value relation)? But Lewis has an answer: naturalness helps determine reference because the reference relation just is a relation involving naturalness (the "most natural" grammar) among other things: call it the naturalness-plus relation. Maybe now Horgan and Graham will ask for an explanation of the identity between the reference relation and the naturalness-plus relation. But I do not think Lewis needs to supply one, because in general identities cannot be explained. Of course, it is sensible to ask for an explanation of the corresponding metalinguistic fact: the fact that "reference" refers to the naturalness-plus relation. And here Lewis can provide an explanation that invokes his own theory of reference: "reference" bears the naturalness-plus relation to the naturalness-plus relation. This kind of self-subsumption is not circular in any metaphysical sense (a point repeatedly made in the literature spawned by Putnam's model-theoretic argument).

31. An alternative solution to the problem of evidence would appeal to Karl's behavioral dispositions. Maybe his behavioral dispositions, together with the behavior-rationalization principle, determine the contents of Karl's immediate perceptual beliefs. Then, given the humanity constraint, the contents of his experiences (and hence, given intentionalism, what experiences he has) are those that make those perceptual beliefs rational. But this suggestion faces the problem of deviant interpretations (Pautz 2010a: 56-57). Moreover, it is at odds with Lewis's solution to that problem. According to Lewis's humanity principle, Karl's history of experiences and hence evidence play a crucial role in constitutively determining the contents of his beliefs. Given this, what experiences and evidence he has cannot in turn be pinned down by his beliefs. That would be circular. To avoid circularity, his experiences and their contents must be determined in a belief-independent way, for instance, by causal connections to the world.

32. On Kriegel's intriguing and innovative version of interpretivism about unconscious intentional states, you have a certain unconscious intentional state iff (very roughly) you are disposed to get a fully informed ideal interpreter in ideal conditions to interpret you as having that state (for full details, see Kriegel 2011: chap. 4). There are important differences between phenomenal functionalism and Kriegel's theory. First, phenomenal functionalism is more general, since it is meant to apply to all conscious intentional states as well, with the exception of sensory experiences. (Kriegel tells me that if he followed me in rejecting the idea that such conscious intentional states are constituted by cognitive phenomenology, then he would take a similar view.) Second, Kriegel's theory is observer-dependent and so faces the usual prima facie counterexamples. Consider a community of killer believers, who have beliefs but are disposed to emit rays (or whatever) that destroy (ideal or other) interpreters when they are about to become informed about them. (This is analogous to Saul Kripke's unpublished case of killer yellow.) Phenomenal functionalism avoids such problems because it does not appeal to an ideal interpreter. There are objective, observer-independent facts about your (conscious and unconscious) beliefs and desires and the semantic values of your expressions, because there are objective, observer-independent facts about what the best interpretation is (or, in case of ties, the set of interpretations tied for best).

33. On Lewis's own view (1974: 117), mental content is always prior to linguistic content. By contrast, as my examples here suggest, I think that in some cases (for example, perceptual content) mental content is prior to linguistic content, while in other cases (for example, arithmetical content) linguistic content is prior to mental content. However, as Lewis notes, his basic theory (and hence my modified version of his theory) is in fact compatible with a mixed view of this kind (he calls it "method 3").

34. Do our zombie twins count as having any beliefs or desires at all, despite not having the capacity for experience? Many would say they do. By contrast, I find it intuitive that they do not. (Smithies (ms) develops an interesting argument against Zombie belief; but it relies on the CP-determination thesis that I have argued against.) This may be a semantic issue, since we agree about the fundamental facts of the case. However, even if we allow that the zombies have beliefs and desires (or beliefs* and desires*), the crucial 
point is that phenomenal functionalism entails that they cannot have the same beliefs and desires that we have (since they lack acquaintance with conscious states and sensible qualities), and that it is at best radically indeterminate what their true contents are.

35. In response to this "epistemic gap" argument, those who think that zombies might have beliefs and desires that determinately possess certain contents might reply that it has such determinate beliefs and desires even if I am right that an ideal interpreter could not deduce them a priori from the fundamental physical facts about its situation. In other words, they might advocate a posteriori physicalism about the alleged determinate beliefs and desires of zombies. Soames (1998) takes a view of this kind about our own beliefs and desires. But to make this credible one would have to least sketch physicalist theories (perhaps a posteriori physicalist theories) of the belief relation and the desire relation which explain how the purely non-phenomenal, non-intentional physical facts about the zombies determine that it comes to determinately bear these relations to some contents rather than others. The history of failed attempts to sketch such theories provides strong grounds for doubting that one can be provided.

36. Schwitzgebel (2002) defends "phenomenal dispositionalism." Speaks (2011) proposes a Horwichian use theory, supplemented with facts about the contents of perceptual experiences. Chalmers (2008) flirts with a "combined view" on which belief content is grounded in sensory/perceptual intentionality and inferential role. Unlike these authors, I provide a general analysis (in terms of the notion of a "best interpretation") of what it is to stand in the belief relation or the desire relation to an arbitrary proposition. This provides a rule for going from the sensory-functional facts about any individual to what the individual believes and desires. I think that such a general algorithm is needed to explain how it is that an ideal interpreter, merely on the basis of his grasp of the concepts of belief and desire (and other relevant concepts), would in principle have the ability to work out any individual's beliefs and desires, given the sensory and functional facts about that individual. Such abilities are not miracles (Braddon-Mitchell and Jackson 2007: 165-166).

\section{References}

Alston, W. 1999. Back to the Theory of Appearing. Philosophical Perspectives 13: 181-203.

Boghossian, P. 1989. The Rule Following Considerations. Mind 98: 507-549.

Braddon-Mitchell, D. and F. Jackson. 2007. Philosophy of Mind and Cognition (2nd ed.). Oxford: Blackwell.

Byrne, A. 2011. Knowing That I Am Thinking. In Self-Knowledge, ed. A. Hatzimoysis. Oxford: Oxford University Press.

Carruthers, P. 2011. The Opacity of Mind. Oxford: Oxford University Press.

Chalmers, D. 2004. The Representational Character of Experience. In The Future for Philosophy, ed. B. Leiter. Oxford: Oxford University Press.

Chalmers, D. 2005. Representationalism Showdown. http://fragments.consc.net/djc/2005/09/ representationa.html.

Chalmers, D. 2006. Perception and the Fall from Eden. In Perceptual Experience, ed. T. Gendler and J. Hawthorne. Oxford: Oxford University Press.

Chalmers, D. 2008. The Critique of Pure Thought. http://consc.net/powerpoint.html.

Cohen, J. 2009. The Red and the Real. Oxford: Oxford University Press.

Dorr, C. 2007. There Are No Abstract Objects. In Contemporary Debates in Metaphysics, ed. T. Sider, J. Hawthorne, and D. Zimmerman. Malden, MA: Wiley-Blackwell.

Dretske, F. 1995. Naturalizing the Mind. Cambridge: MIT Press.

Fodor, J. 1994. The Elm and the Expert. Cambridge: MIT Press.

Goff, P. 2012. Does Mary Know I Mean Plus rather than Quus? Philosophical Studies 160: 223-235. 
Graham, G., T. Horgan, and J. Tienson. 2007. Consciousness and Intentionality. In The Blackwell Companion to Consciousness, ed. M. Velmans and S. Schneider. Oxford: Basil Blackwell.

Graham, G., T. Horgan, and J. Tienson. 2009. Phenomenology, Intentionality, and the Unity of Mind. In Oxford Handbook of Philosophy of Mind, ed. A. Beckermann and B. McLaughlin. Oxford: Oxford University Pres.

Hill, C. 2009. Consciousness. Cambridge: Cambridge University Press.

Hill, C. 2012. Locating Qualia: Do They Reside in the Brain or in the Body and the World? In New Perspectives on Type Identity: The Mental and the Physical, ed. S. Gozzano and C. Hill. Cambridge: Cambridge University Press.

Horgan, T. 2010. Materialism, Minimal Emergentism, and the Hard Problem of Consciousness. In The Waning of Materialism, ed. G. Bealer and R. Koons. Oxford: Oxford University Press.

Horgan, T. and G. Graham. 2010. Phenomenal Intentionality and Content Determinacy. In Prospects for Meaning, ed. R. Shantz. Amsterdam: de Gruyter.

Horgan, T. and J. Tienson. 2002. The Intentionality of Phenomenology and the Phenomenology of Intentionality. In Philosophy of Mind: Classical and Contemporary Readings, ed. D. Chalmers. Oxford: Oxford University Press.

Horgan, T., J. Tienson, and G. Graham. 2004. Phenomenal Intentionality and the Brain in a Vat. In The Externalist Challenge: New Studies on Cognition and Intentionality, ed. R. Shantz. Amsterdam: de Gruyter.

Johnston, M. 2007. Objective Mind and the Objectivity of Our Minds. Philosophy and Phenomenological Research 75: 233-68.

Kripke, S. 1982. Wittgenstein on Rules and Private Language. Oxford: Blackwell.

Kriegel, U. 2011. The Sources of Intentionality. Oxford: Oxford University Press.

Levine, J. Forthcoming. On Phenomenal Access. In Themes from Block, ed. A. Pautz and D. Stoljar. Cambridge: MIT Press.

Lewis, D. 1972. Psychophysical and Theoretical Definitions. Australasian Journal of Philosophy 50: 249-258.

Lewis, D. 1974. Radical Interpretation. Synthese 21: 331-344. References are to the version reprinted with a postscript in D. Lewis Philosophical Papers: Vol. I (Oxford: Oxford University Press, 1983).

Lewis, D. 1983. New Work for a Theory of Universals. Australasian Journal of Philosophy 63: 343-377.

Lewis, D. 1992. Meaning without Use. Australasian Journal of Philosophy 70: 106-110.

Lewis, D. 1994. Reduction of Mind. In A Companion to the Philosophy of Mind, ed. S. Guttenplan. Oxford: Blackwell.

Loar, B. 1981. Mind and Meaning. Cambridge: Cambridge University Press.

Lycan, W. 2001. The Case for Phenomenal Externalism. In Philosophical Perspectives, Vol. 15: Metaphysics, ed. J. E. Tomberlin. Atascadero, CA: Ridgeview.

Lycan, W. 2009. Giving Dualism Its Due. Australasian Journal of Philosophy 87: 551-563.

Mendelovici, A. 2010. Mental Representation and Closely Conflated Topics. PhD Dissertation, Princeton University.

Montague, M. 2010. Recent Work on Intentionality. Analysis 70: 765-782.

Pautz, A. 2006. Sensory Awareness Is not a Wide Physical Relation. Noûs 40: 205-240.

Pautz, A. 2008. The Interdependence of Phenomenology and Intentionality. The Monist 91: $250-272$.

Pautz, A. 2010a. A Simple View of Consciousness. In The Waning of Materialism, ed. G. Bealer and R. Koons. Oxford: Oxford University Press.

Pautz, A. 2010b. Do Theories of Consciousness Rest on a Mistake? Philosophical Issues 20: $333-367$.

Pautz, A. 2010c. Why Explain Visual Experience in Terms of Content? In Perceiving the World, ed. B. Nanay. Oxford: Oxford University Press.

Pautz, A. 2011. Can Disjunctivists Explain Our Access to the Sensible World? Philosophical Issues 21(1):384-433. 
Pautz, A. forthcoming. Phenomenal Intentionality: A New Argument against Materialism? In New Waves in Philosophy of Mind, ed. J. KalleStrup and M. Sprevak. Palgrave.

Pitt, D. 2009. Intentional Psychologism. Philosophical Studies 146: 117-138.

Pitt, D. 2011. Introspection, Phenomenality and the Availability of Intentional Content. In Cognitive Phenomenology, ed. T. Bayne and M. Montague. Oxford: Oxford University Press.

Quine, W. 1960. Word and Object. Cambridge: MIT Press.

Russell, B. 1912. The Problems of Philosophy. London: Williams \& Norgate.

Schiffer S. 2006. Propositional Content. In The Oxford Handbook of Philosophy of Language, ed. E. Lepore and B. Smith. Oxford: Oxford University Press.

Schwitzgebel, E. 2002. A Phenomenal, Dispositional Account of Belief. Noûs 36: 249-275.

Siewert, C. 1998. The Significance of Consciousness. Princeton: Princeton University Press.

Siewert, C. 2011. Phenomenal Thought. In Cognitive Phenomenology, ed. T. Bayne and M. Montague. Oxford: Oxford University Press.

Smart, J. C. 1959. Sensations and Brain Processes. Philosophical Review 68: 141-156.

Smithies, D. MS. The Mental Lives of Zombies.

AQ: Please identify this work. Is it a ms? Google says "draft only."

Please don't cite or circulate without permission.
Soames, S. 1998. Skepticism about Meaning, Indeterminacy, Normativity, and the Rule-Following Paradox. Canadian Journal of Philosophy, Supp 23: 211-250.

Speaks, J. 2011. Can We Explain Linguistic Representation in Terms of Perceptual Representation?

Stalnaker, R. 2004. Lewis on Intentionality. Australasian Journal of Philosophy 82: 199-212.

Strawson, G. 2010. Mental Reality, 2nd ed. Cambridge: MIT Press.

Swoyer, C. 1982. The Nature of Natural Laws. Australasian Journal of Philosophy 60: 203-223.

Tye, M. 2000. Consciousness, Color and Content. Cambridge: MIT Press.

Tye, M. and B. Cutter. 2011. Tracking Representationalism and the Painfulness of Pain. Philosophical Issues 21:90-109.

Weatherson, B. Ms. The Role of Naturalness in David Lewis's Theory of Meaning. http://brian. weatherson.org/papers.shtml.

Williams, R. 2008. Eligibility and Inscrutability. Philosophical Review 116: 361-399.

Williamson, T. 2000. Knowledge and Its Limits. Oxford: Oxford University Press. 